\title{
FASHIONING DECOLONIZATION: TELLING STORIES OF CANADIAN INDIGENOUS WOMEN THROUGH FASHION HACKING
}

\author{
by \\ Presley Mills, \\ BDes, Alberta University of the Arts, 2016 \\ DBA, Southern Institute of Technology, 2013 \\ A MRP \\ presented to Ryerson University \\ in partial fulfillment of the \\ requirements for the degree of Masters of Arts \\ in the program of Fashion \\ Toronto, Ontario, Canada, 2019 \\ (C) Presley Mills, 2019
}




\section{ABSTRACT}

Decolonization is a complex, often discussed in academic or political environments, it is challenging to discover tangible ways for individuals to practice it in daily life. A gap between the personal understanding decolonization and the academic definitions of decolonization was identified through oral history interviews, so this research shares the unique stories of eight Canadian indigenous women through fashion as a way to inform a more accessible and embodied definition of decolonization. The participants took part in a fashion-hacking workshop to began to answer the questions: What does the lived experience of decolonization look and feel like for Indigenous women? How do Indigenous women think about decolonization in the personal aspects of their life and how can that be expressed through fashion? The format of this paper explores different perspectives and ways of knowing by jumping back and forth between storytelling, art, Indigenous and Western academic research. 


\section{ACKNOWLEDGMENTS}

This research has been a journey and will continue forward into my daily life. Firstly, I would like to thank the participants, Gladys, Pauline, Sarena, Charlene, Alysia, Alexandria and Destiny, who shared their time and experiences with me. I learned so much from them and was inspired by their stories.

I could not have done this research without the endless support and positivity of my supervisor Dr. Ben Barry. Thank you for helping me decipher so many complex ideas and emotions, guiding me to new perspectives, and for encouraging me to follow my instincts and creative voice without compromise.

Thank you to my second reader Joseph Medaglia, my friends and colleagues, the many professors in the Ryerson School of Fashion, Logan, my family, Pearls, coffee, blueberries, podcasts, and Tracy Martel for keeping me thinking, inspired and motivated. 


\section{AUTHOR'S DECLARATION FOR ELECTRONIC SUBMISSION OF A MRP}

I hereby declare that I am the sole author of this MRP. This is a true copy of the MRP, including any required final revisions.

I authorize Ryerson University to lend this MRP to other institutions or individuals for the purpose of scholarly research.

I further authorize Ryerson University to reproduce this MRP by photocopying or by other means, in total or in part, at the request of other institutions or individuals for the purpose of scholarly research.

I understand that my MRP may be made electronically available to the public. 


\section{TABLE OF CONTENTS}

\section{Introduction}

\section{Part 1: Discovery \& Storytelling}

5 My story \& The Métis story

7 What does it mean to be Métis?

12 Gladys' Story: Assimilation \& dead Indian myths

16 Pauline's Story: Reclamation, Reconciliation and Re-education

19 Finding Common Language

20 WTF is Decolonization

\section{Part 2: Making \& Action}

22 Methodology

29 Sarena

32 Charlene

35 Alysia

37 Alexandria

39 Destiny

41 Presley

43 Activity Design Reflection

45 Moving Forward

\section{Appendix}

49 Appendix 1: Recruitment Materials

51 Appendix 2: Workshop Inspiration Cards

54 Appendix 3: Participant Consent Form

59 Appendix 4: Workshop Plan and Materials

60 Appendix 5: Post Workshop Resources

62 Works Cited 
Fashioning Decolonization: Mills

This page was intentionally left blank. 


\section{Introduction}

This paper looks different and this research is personal. Based on the research of Shawn Wilson (2008), in the book Research is Ceremony: Indigenous Research Methods, the research and creative work are practising Indigenous methodologies as a form of decolonization. My writing explores different perspectives and ways of knowing by jumping back and forth between storytelling, art, and Western academic research. Referencing Wilson's (2008) style of writing, the serif font indicates the "academic" portions and the sans-serif or script fonts are used in the more personal or narrative sections. My identity is reflected in the style of this research: Métis people are at a unique position of in-between-ness and with a common narrative of awareness of being raised outside a traditional community (Andrews, 2002). The paper is in-between two worlds; traditional academia and Indigenous forms of knowledge. This approach prioritizes collaborative work with Indigenous people, rather than studying from a distance which has historically been a problematic approach in Western Indigenous studies. Storytelling and making have taken a prominent role at beginning to answer the research questions: What does the lived experience of decolonization look and feel like for Indigenous women? How do Indigenous women think about decolonization in the personal aspects of their life and how can that be expressed through fashion? Can making fashion expand our understanding of decolonization? Can fashionhacking be a decolonizing practice?

Stories have often been used in Indigenous societies as teaching tools as "stories allow the listener to draw their own conclusions and to gain life lessons from a more personal perspective" (Wilson, 17, 2008). Creative visual practices, such as art, craft and fashion, have the similar ability as spoken stories to communicate personal perspectives through creative storytelling. Storytelling has always played an important role in my life and my personal form of storytelling is visual. Our impact on the world lies in our work, how we present ourselves, where our money is spent, and how we share knowledge. Through research, I began to recognize decolonization as a tool to change how I personally looked at society but also as a tool to help reconstruct a positive native womanhood that has been damaged by colonization. Hearing stories of decolonization felt like medicine and gave me hope that we could heal and move forward from past violence in our common history.

Decolonization is a complex, often discussed in academic or political environments, but it is challenging to discover tangible ways to practice it because society is thoroughly colonized. Often the metaphor of 
decolonization arises when discussing other issues in the realm of social justice (race, gender, equality, other...) but decolonization requires the inclusion and participation of Indigenous people and is always specific to them. According to Tuck \& Yang, "When metaphor invades decolonization, it kills the very possibility of decolonization; it recenters whiteness, it resettles theory, it extends innocence to the settler, it entertains a settler future. Decolonize ( a verb) and decolonization (a noun) cannot easily be grafted onto pre-existing discourses/frameworks" $(3,2012)$. That is why decolonization must be practised by Indigenous people constantly, with intention and awareness. It can only be realized through our choices and unsettling existing social constructs.

Prior to the 1800s, settlement was not the priority of Europeans nations in North America. Once the supply of furs and meat had dwindled and the demand had decreased, they began to settle the 'New World' for farming. This began the process of assuming control of Indigenous territory and forcibly applying their own laws, government and religion on the inhabitants. Fashion has been used as a weapon of colonization to suppress and control Indigenous people. The Indian Act suppressed the expressions of Indigenous culture through the ban of ceremonies, dances, and sacred items, but also through aggressive assimilation practices like residential schools where Western dress was strictly enforced (Facing History and Ourselves, 2019). Fashion is one of the most universal daily choices everyone makes and it is also a visual display of our identity and position in society. This made fashion an ideal medium to explore people's personal identity and gain an understanding of their current interpretations of decolonization. 


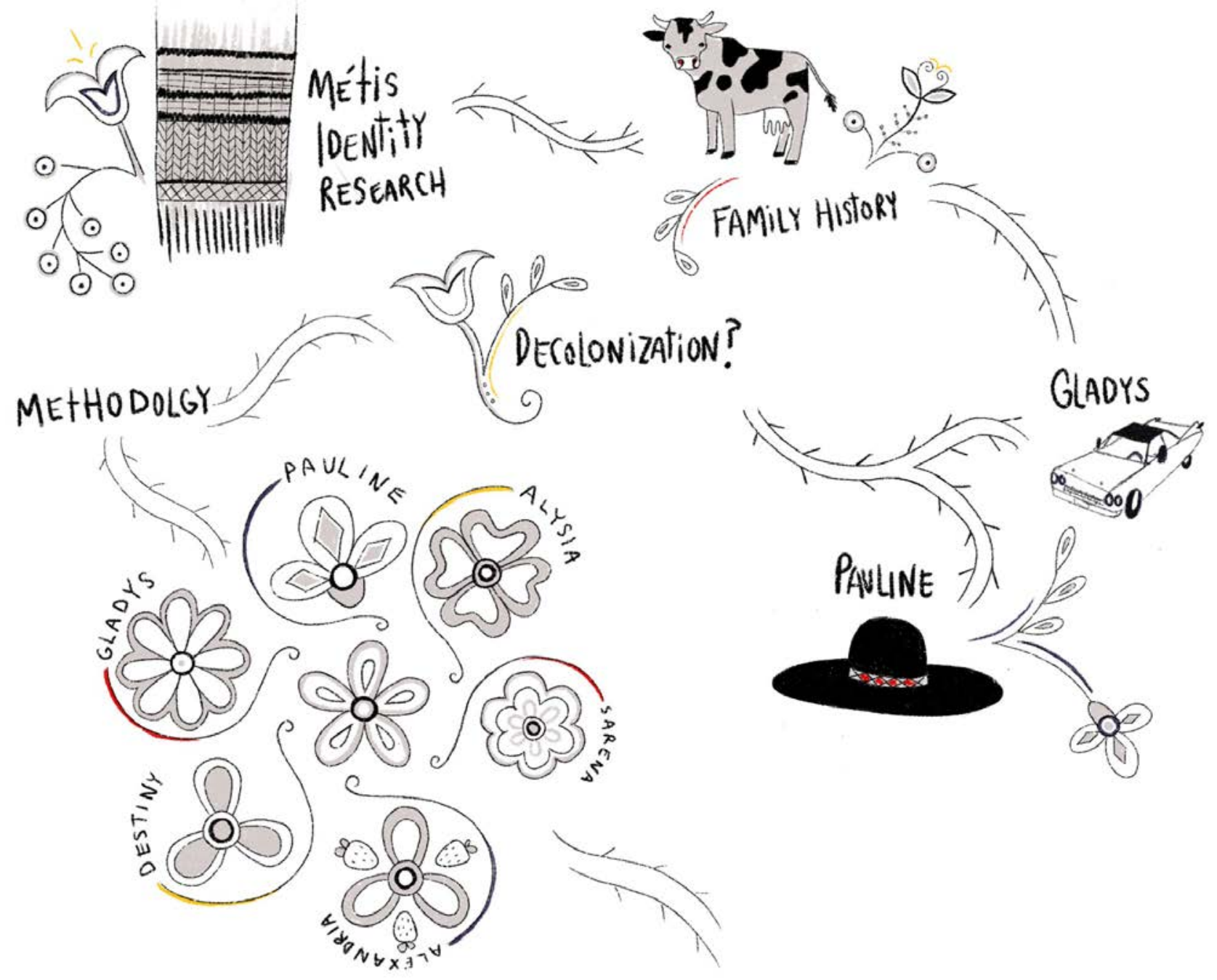

To outline the journey of my research, I begin by introducing my own story and how that connects the larger context of Métis identity. After realizing some shortcomings when discussing identity and decolonization, I chose to seek out oral histories and guidance from Elders in my home province. My initial interviews were with Elders in Alberta. Getting approval to speak to them gave me ideas of how academia needs to account for decolonizing research practices. But also, speaking to the Elders exposed a lack of understanding they experienced when it came to the word 'decolonization'. Talking with them helped inspire the research question and inspired the direction to create a fashion-hacking workshop. In this paper, I will explain how the workshop was designed to create a collaborative space for participants to help answer "what is the lived experience of decolonization". The voices of the participants are presented alongside illustrations 
of their creation. For the entire paper, I chose to use illustrations rather than photographs. As soon as I interviewed the Elders in the summer, I knew that I had to display what they were showing me in a different way. Their stories were so complex and the photos I took of what they showed me didn't do justice to viewing them in person. Instead of showing mediocre photos, I chose to interpret how I saw them through illustration. As mentioned throughout the paper, written words fall short in expressing the complexity and the relationships developed through oral tradition and collaborative research. I hope the illustrations support how this research is personal, based on personal experiences, and contributes to the dialogue between Western and Indigenous research methods. Making was used as a way of knowing and sharing information, that like storytelling, allows room for personal interpretations... of interpretations. This project explores the story of eight Indigenous women and poses how to continue this research through fashion.

As Leclair describes in Memory alive: race, religion, and Métis identities, "Words and phrases such as originary discourses of self-representation, essentialism, naive empiricist methodologies, pretheoretical, postmodernism, and monoculturalist multiculturalism are not very useful when I speak of Metis realities. Ask a Metis elder/intellectual (in Michif, saprawn chimawkakayhtamik ouma, "one who must think things through") a question about essentialism, for example, and the response will often begin with "Maybe I can answer best by telling this story...." $(159,2002)$. This is why I have chosen explore this research in a way that prioritizes storytelling, accessibility, and personal experience. 


\section{Part 1: Storytelling \& Discovery \\ My story \& The Métis story}

I begin this paper by talking about myself and my inspiration because I want to practice the Indigenous method of contextualized knowledge. My time, place, and environment have greatly affected my focus and approach to doing research in the field of fashion.

My grandma and I had a lot in common. We were both introverted-extroverts driven to create things. We were very close and I spent a lot of time with grandma, as both my parent had to work or go to school when I was little. I was lucky to spend a lot of time running around grandma's house. Her house was full of mysteries to discover: drawers of clothing, baskets of sewing scraps and tools, a massive record player, a cupboard full of raisins and marshmallows, and a garden that was my second home. My grandma loved to tell stories, but never stories about herself. Later in life, I began to understand why she kept her stories secret. What I did know was:

Grandma was an amazing baker. She always had fresh bread or butter tarts on the go. She would let me roll out the dough to make cookies and crusts when I was little, but my favourite part was eating. We still are trying to recreate her fresh bread smeared with butter, but I can't quite match hers. That love for cooking still follows me.

Grandma was a maker. She always had a random project on the go where she would throw together random things. She would destroy something to make something new. It wasn't always better but it was certainly was unique. This love and fearlessness for making still follows me.

Grandma had style. Her looks were glamorous and almost always in bright shades of pink and purple. She was slim, tall and elegant. Her silver hair was always perfectly curled. She loved to dress up in glamorous outfits or just silly costumes usually that she made herself. This love for fashion still follows me.

Grandma was the best gardener. I loved the summer when the hollyhocks bloomed all along the back of her house. There was the biggest raspberry bush to snack from 
and a secret garden that I would go hide in and try to spot fairies.

Now my family has a beautiful garden to grow food in, but also a memorial garden that began with a rosebush for her.

Her love for nature still follows me.

Grandma has been one of the greatest influences in my life, but she wasn't perfect and had her own struggles. I see these same things in myself and all the women in my family. Our blood carries memories of our histories, wisdom, shared passions and family traits, but there are huge pieces missing. I would describe what I learned from grandma as stories taught

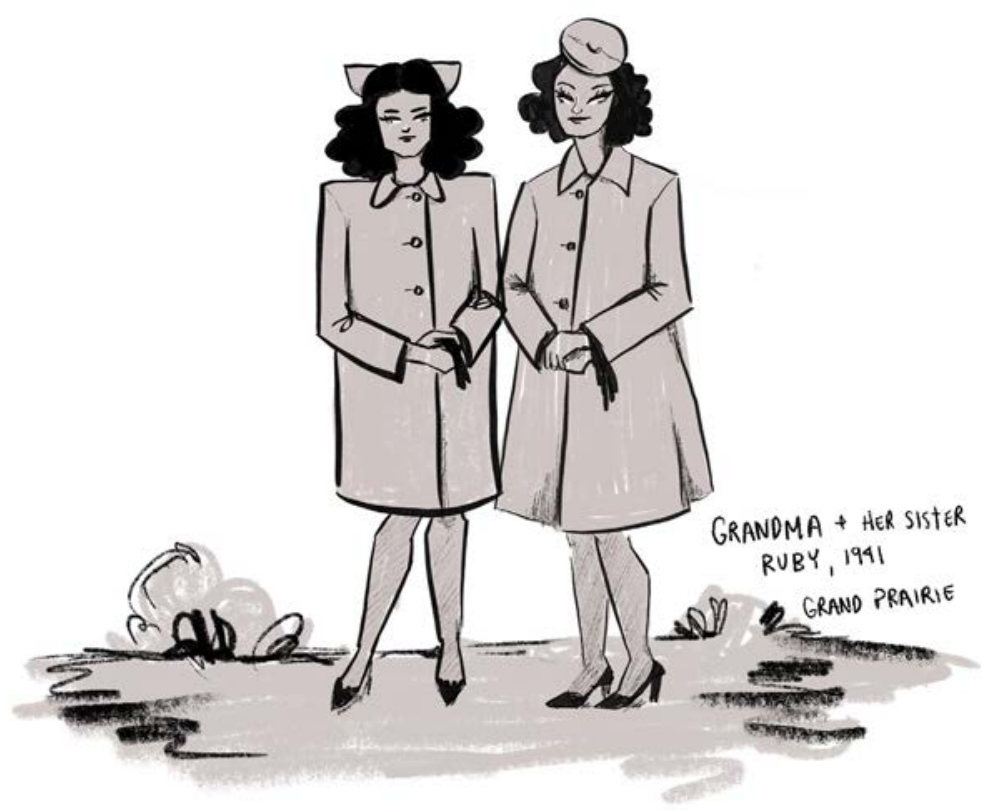
without context. The same way grandma gave me these positive memories that I cherish, the not-so-positive ones from her and my mother still follows me. I am lucky to have information now, that my grandma didn't want to share. I know now that her first language was Cree and great-grandma spoke Cree and French before she learned English later-on in life. I know that each generation in my family became more and more assimilated into Western culture because it was encouraged by the community at large. I have always known we are Métis, but until recently I never understood it personally or how complex of an identity it is in the greater context of Canada.

There is a shared contemporary experience among Indigenous people in Canada, where there is a sense of uncertainty, shame, or loss regarding their identity. Kim Anderson (2000), who has a similar experience as a Métis woman explains, "Like many Native people, I struggle with my identity. Because of racism, cultural genocide and policies that have encouraged Native people to abandon their heritage, many of us have come to feel ashamed, confused or embarrassed about identifying ourselves as Native. From this confusion, we must struggle to re-name ourselves to understand what that means" (23). 


\section{What does it mean to be Métis?}

Logan defines Métis, not based on genetics, but on the distinct community rooted in a historic lifestyle “involved seasonal hunting, periodic return to fixed trading bases, and mobile art forms of song, dance, fiddle music, and decorative clothing' and the Michif language that blends French and Aboriginal languages in a unique way (Logan, 74, 2019). Since the repatriation of the Canadian Constitution in 1982, the inclusion of Métis as a recognized Aboriginal people as created uncertainty defining who are Métis people. "In the legal and political contexts of the early Twenty-First century, the question of who is Métis is not answered simply by determining whether one is of mixed Aboriginal and white ancestry but, rather, by determining how this is so, from whom one is descended, and from where one originates" (Barman, Jean \& Mike Evans, 3, 2009). The Powley Decision in 2003, a court case affirming Métis rights to the Métis community in and around Sault Ste. Marie, Ontario, resulted in a test to determine if an individual meets the major criteria to be Métis. The first criteria is to identify as a Métis person; be a member of a present-day Métis community; and, have ties to a historic Métis community. The secondary test is more complicated. "In Powley, the Supreme Court of Canada stated the term Métis in s. 35 does not encompass all individuals with mixed Indian and European heritage. Rather it refers to a distinctive people who, in addition to their mixed ancestry, developed their own customs and recognizable group identity separate from their Indian or Inuit and European forbearers. The Métis communities claiming Aboriginal rights must have emerged in an area prior to the Crown affecting control over a non-colonized region” (Government of Canada, 2018). This is complicated for multiple reasons today as two-thirds of the Métis population do not live in Métis communities (Stats Can, 2017), because of the assimilation practices of colonization. This Government definition is not inclusive of those who fit the definition of individuals of mixed descent and organizations "appropriated this language to support their rights-based political agendas, which has inadvertently under-mined discourses on peoplehood" (Andersen, 2014). This results in individuals deserving of the same Aboriginal right being excluded from discourse and also fosters a system that is distrusted by many Indigenous people because it is founded on colonial values. Métis individuals, therefore, may choose not to subscribe to an official Métis organization, resulting in them failing the Powley criteria.

The construct of Métis is also based on a complex combined history of settler and Indigenous people developing their own unique culture across what is now Canada. Coming from Alberta, the definition of 
Métis is slightly more defined by a large number of people who identify in accordance with the sociopolitical 'Métis'. There is less focus on race and more on kinship and common culture. Outside the Prairie provinces, the capital M Métis versus small $\mathrm{m}$ métis is less clear. The word métis/métisse is the French word for halfbreed or mixed; it wasn't widely used until the 1970s for the repatriation of the constitution as the English socio-cultural or political term. The anglicized pronunciation of "may-TEA" has links to those who connect specifically to Métis culture. On the farthest end of the spectrum for defining Métis are those who believe only people with descendants of the Red River Métis are legitimately Métis. These definitions are sometimes overlapping, separate or any other sort of anomaly. This makes it very complicated to define 'Who is Métis'.

Currently, many Native scholars (such as Eve Tuck, Thomas King, and Joe Sawchuk mentioned in this research) are questioning the current system and definition of Métis peoplehood because of the lack of contemporary consensus about what constitutes of Métis identity. Research examining Métis identity discuss the implications of genocide in North America and how the on-going policing of identity is a way to continue the suppression and destruction of Indigenous culture. Contemporary Canadian politics attempt to veil their checked-past by recognizing Métis organizations and people, who had been "depicted negatively or ignored altogether within traditional narratives of Canadian history" (Andrews, 2002). "The effects [of colonization] on current Native populations are multifaceted, including political, economic, emotional, social, cultural, mental, and perhaps most importantly, spiritual" (Fountaine, 184, 2017). This dilemma is summarized by Sawchuck (2001) in Negotiating Identity: "Struggles for self-definition by aboriginal minorities against an encompassing nation-state are fraught with irony. The very process of declaring oneself to be "Métis" (or "Indian" or "Inuit") means taking on aspects of identity and otherness that have been defined by the dominant society. Such irony has been exacerbated by academics, who have labelled many of the struggles by contemporary aboriginal peoples to reformulate national cultures and communities as "invention" (Sawchuck , 2001). Because of this political debate, it is challenging to maintain positive self-identity and can foster uncertainty for individuals whose personal experience does not fit into the dominant narrative surrounding their identity. According to Anderson (2000), defining Métis isn't a question of what percentage native you are, which side of our family is indigenous, what language you speak, or why didn't you grow up on a reserve. Métis are a part of a shared experience of relocation, dispossessed ways of life, adoption into white families and an awareness that information our your history is lost (27). 
Thanks to the previously rigid requirements for proving Métis-hood, I have a lot of information on my family. The history of the Lizotte family, great-grandma's parents, is documented in the paper 'Lizottes of Fort Vermilion and pre-1900 Evolution of a Métis Community'. Just reading their history really challenges any questions of blood-quantum, because it is impossible to mathematically calculate "how much native" anyone is. The paper explores the roles of the family within the community through trading post journals, but it is clear huge portions of this story are missing. In a family of 13 children, 9 of whom were women, only the stories of the men are explored. Also, the census of the area only counted the 'Half Breeds', but based on some of the marriages documented and the dominant language it suggests that the community in and around Fort Vermilion was largely Cree and Dene. The first language of the Lizottes was Cree and French, and many of the men are documented to speak multiple languages including Cree, French, English,

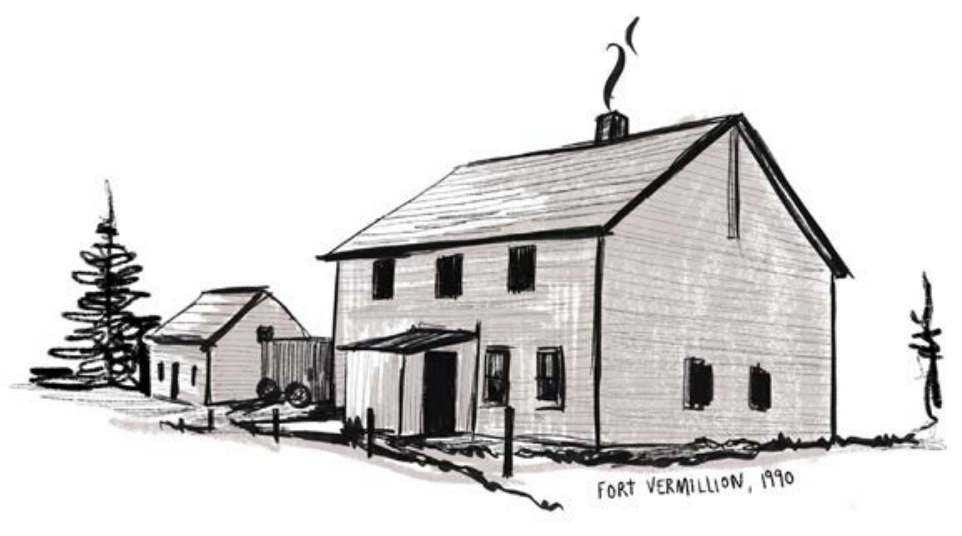
Beaver, and Chipewyan. The matriarch of the family Sophie Tourangeau was a devout Roman Catholic and seemed to have caused some strife in the community after the arrival of the Protestant mission in 1875. Being a study of fashion and art, the two mentions of clothing and craft stick out to me. The first is Sophie making a dress for a towns girl so that she could attend the Catholic church instead of her family's Protestant church. The second was the mention of Rose, great-grandma's mother, owning two cows, two horned animals, and being remembered for her embroidery and handicrafts (Ferguson, 2008). Anyone who knows me knows of my deep love for cows and obviously, the link to craft was pretty exciting to read.

My grandma grew up in Fort Vermilion, where her family continued to run a trap line and manage the trading post. My grandma's seven siblings were all close. Over the years they all moved to different areas in Alberta. My mum tells me about when they would get together, the girls would gather whispering until they would burst out in fits of laughter. When my mum was growing up, the families would come together for the summer in Akitameg, a community south of Fort Vermilion. Akitameg is Cree for White Fish, which is how my mother referred to the place. 


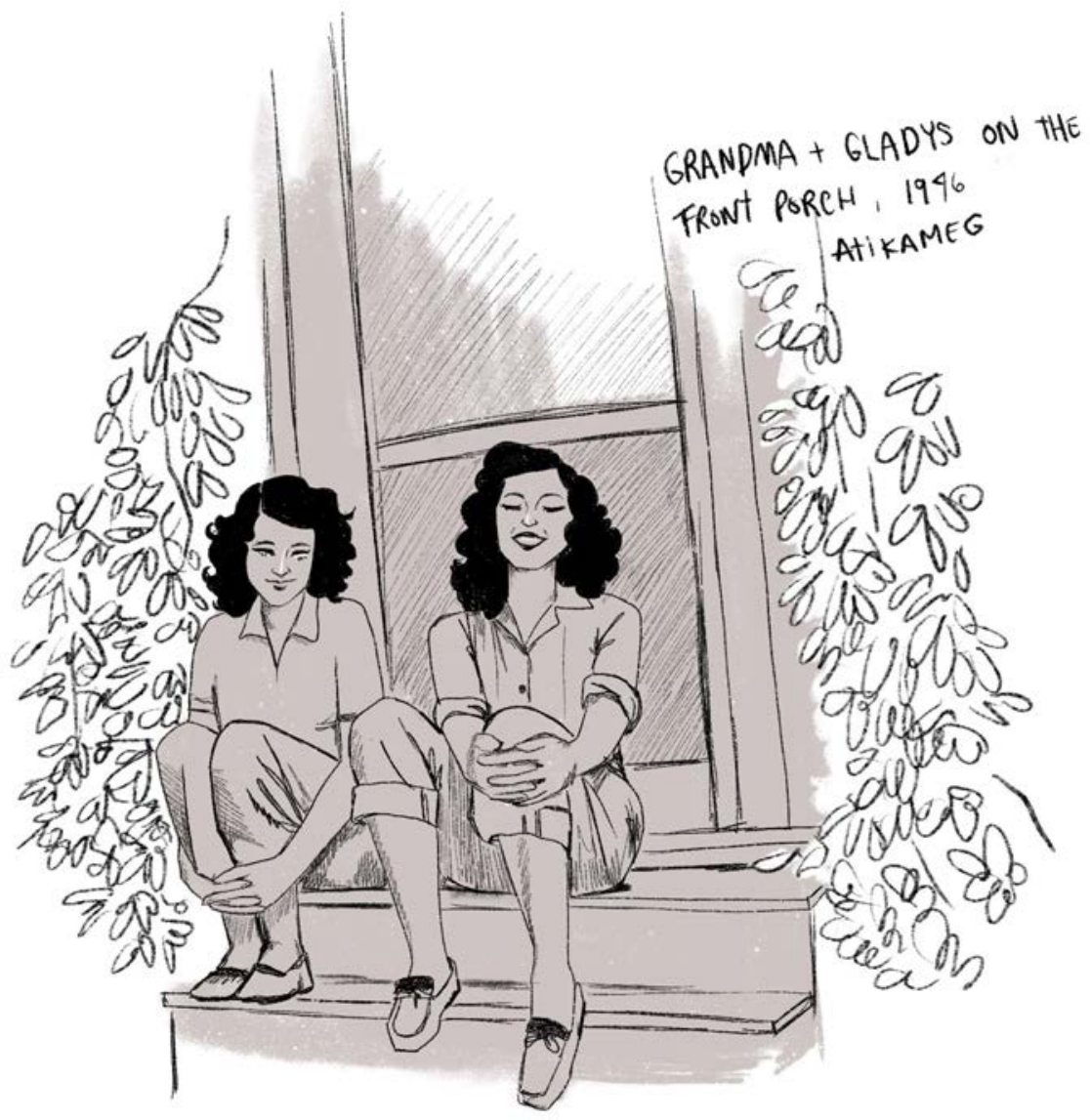

Whitefish instead of Atikameg is a clue to the mindset of my grandma's generation. Grandma was not raised to take pride in any Native heritage or traditions. It was something for the older generations, but not the kids or outside world. Right before we lost my grandma, she tried teaching us Cree. I've been told great-grandma fully switched to speaking Cree in her last few years as well. These hidden parts of their lives only becoming visible at the close. Starting with my mother's generation, who mainly grew up outside of Fort Vermilion area, there has been a constant desire for more information. The older generation would share something then close back up when pressed for more.

I grew up in Blackfoot territory: Calgary or... Cowtown. Since leaving Calgary I have really missed aspects of it, but also have gained a new perspective on how I was taught about Indigenous culture there. Calgary is like any other Canadian city, except for once a year it turns into a highdrag-cowboy-party city for two weeks. The Calgary Stampede is a huge rodeo and fair that seems to take over the entire city. Growing up I was used to seeing Indigenous people in parades and 
going to Pow Wows and dances, but all within the context of the Calgary Stampede. Because of this, I conflated Cowboys and Indians with the overall 'show' of the Stampede. It made me feel insecure about calling myself Métis. I am white presenting, did not grow up on a reserve, I have mainly participated in Indigenous culture as an observer and my main links to the culture are through the making skills grandma taught me and a few items of clothing. My perspective of Métis culture was frozen in time. It was almost as if the version of Métis people had to be images from a history book, but nothing else. I wasn't an idealized version of a Native person, depicted in paintings of the Old West, so I felt guilty about identifying as Métis. 


\section{Gladys' Story: \\ Assimilation \& Dead Indian Myths}

Thomas King (2012) in The Inconvenient Indian:

A Curious Account of Native People in North America, speaks of the 'Dead Indian' as the only image that

North America has of Indigenous people. Depictions of native people in war bonnets, fringed deerskin dresses, tomahawks, face paint, moccasins, bone chokers are the bit of 'cultural debris' or signifiers that comfort non-native

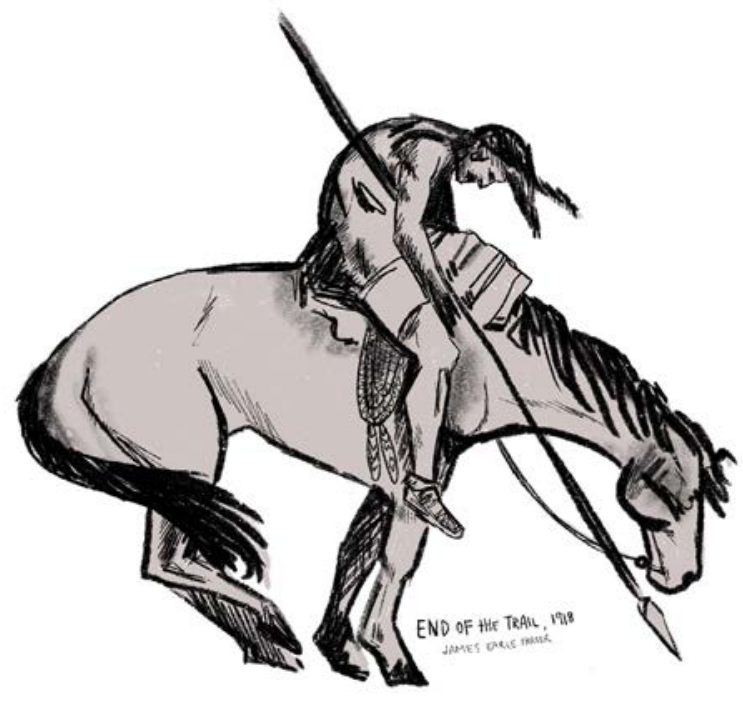
people because they are associated to the idea of extinct people who are relics of the past. These were the people who were supposed to die-out through the process of colonization. They were remnants of the past and the Dead Indian represented the colonizers' success. For example, the statue The End of The Trail, by James Earle Fraser has been a long-standing icon of Indigenous people dejected and concurred by 'civilization'. The Dead Indian were depicted as noble, silent, caricatures, while the Live Indians were invisible, unruly and couldn't be used to create a romantic narrative of North America. The problem was Live Indians still exists. In the book 'The Inconvenient Indian” King discusses the intention of colonization: to erase Indigenous people. The colonizers hoped their strategies would wipe out the entire population but Indigenous people remain (2012). Recognition of the Live Indians in today's society is an important form of resistance.

At the beginning of this project, I had decided to explore how Métis identity intersects with fashion. Returning to Alberta for the summer, my intention was to interview people and travel around the province, perhaps making it to Fort Vermillion. Life doesn't go as plan sometimes and that didn't happen. I found it terrifying to reach out to people and I felt that my entire project was the wrong choice. As someone with so little connection to their Indigenous background, I felt I had no right to explore this topic. I felt lost. I finally forced myself to try. I started with the easiest thing, which was to go visit my great-aunt in Edmonton. She is the youngest of my Grandma's sisters (at 91 years old) and the only one remaining. I spent the day at a greenhouse with her 
and another family member, looking at plants and having lunch. We returned to their house so I could interview her. My mum warned me about how to approach the conversation. Gladys doesn't use the word Métis. In her defence, it only became an official term in the 1980s. She was ninety years old when we did the interview, so she was herself before the government 'approved' the term Métis. We talked about her life through her clothing. She has always been a fashionista and photos of her show that she was like a model. Growing up the sisters shared clothing or ordered it from catalogues. Even though the family ran a trap line and farmed mink, only the oldest daughter received a mink shawl for her eighteenth birthday. I was really excited about was Gladys called 'whoopi' pants. She described them as pants like jeans, but they had fringe down the outside seams. The name Whoopi is still a mystery to me but it could be a name they came up with based off woollies, which are a type of protective horseback riding pant with fur or fringe down the leg. They lived on a reserve and travelled by horse and/or sleigh to get anywhere. It was isolated, but she remembers playing baseball with the other kids and she spent lots of time with her siblings and animals. She spoke of wearing moccasins made by people in town. I asked her if she spoke

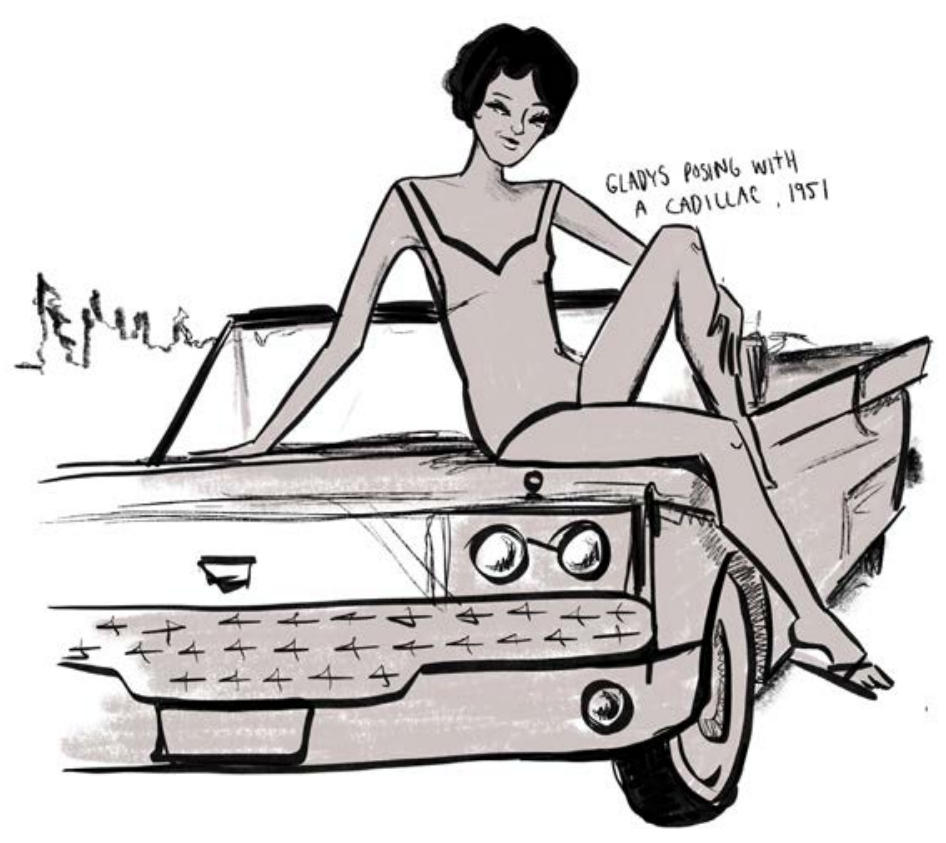
Cree. She said 'Oooh yes, but not anymore'. As a child, they spoke Cree with the other children in town but all the adults made a point of only speaking English to the children, even when they spoke Cree to each other. By the time she was going to school, English had become everyone's first language. All the kids went to school at various Roman Catholic missions in Gouard, Fort Vermillion or Fort Chipewyan.

Gladys had been the rebellious kid of the family; she was slim, fashionable and dressed to make a statement. Right after leaving home, to overcome her shyness she took modeling lessons in Edmonton. They taught her how to apply makeup and do her hair. She really valued begin unique. By the sounds of it, she was always ahead of the times; trying hair extensions, dying her hair every colour and wearing bright and colourful makeup. Living in the big city, Edmonton, she would 
spend her free time watching fashion shows in the department stores and going to dances every weekend. A common trait in the family is to not be very sentimental with their clothing. Like my grandma, Gladys has given away most of her old things. She says she gets bored and always wants to try something new and different.

Interviewing Gladys aided in exposing successful assimilation tactics in Canada that were perpetrated by both settlers and Indigenous people. The most clearly observable was the disintegration of language through each generation of the family. Gladys being the second youngest spent the least amount of time speaking Cree at home and the adults and older siblings made an intentional effort to speak to the younger people in English. Colonization forced the adoption of language, cultural values and religious practices through a process of gradual or violent assimilation (Merkle \& Mallet, 1, 2018). Through interviewing Métis Elders, Logan observed the lasting impacts of residential schools. The Elders recalled how their language was suppressed and culture belittled while in residential schools, resulting in them feeling compelled to teach their children English rather than Michif (Logan, 72, 2019). My family's experience seems to align with the stories recorded in her research, that demonstrate how each generation made a choice to reject or forget their culture thanks to the influence of the nuns who educated them.

From Gladys' interview, I can dissect examples of her shifted world-view that reflected internalized colonization and shame surrounding her Indigenous background. Like my grandmother, Gladys does not want to identify as Métis. Lorena Sekwan Fontaine shares how Canada’s educational system has played a significant role in the destruction of Indigenous language in the article Redress for Linguicide (2017). The Cree language is not a dying language, but my family has personally missed the opportunity to learn the language at home through the influence of assimilation encouraged by the education system. A legacy of residential schools is that "In 2011, only 14 percent of the Indigenous population reported learning their language at home" and "the average age of traditional language speakers is over 60 years, with that average increasing yearly” (Statistics Canada 2011) meaning few indigenous people have the opportunity to learn their ancestral language at home (Fountaine, 184, 2017). The implementation of residential schools was created to remove children from their families so they would be encouraged to give up their culture and way of life. This would solve the 'Indian problem' by the assimilation of entire generations of people into 'civilized' society (Facing History and Ourselves, 2019). 
During the interview, I was cautious to not express my perception of colonialism and place my judgement on her life. Gladys made a choice to adapt and accept her circumstance, which resulted in her receiving better treatment in Residential school. She said that the nuns were mean and would smack you when you got in trouble, but they also liked her more because she was good at speaking English. Gladys leaned into calling herself 'the white one'. Métis people present in a variety of ways and passing as white had its benefits. Many people of that generation accepted the erosion of their culture and identity as a way to avoid racism or as a survival mechanism (Dorion, 1997). We cannot fault her for making that choice but even though it is unpleasant and sad to hear a family member speak in this way. Moving forward it is my choice to reclaim that identity and culture because it is valuable to me.

Tricia Logan says in From Truth to Reconciliation, "Perhaps forgetting aided in the resilience, but now, in an open environment, active remembering and active forgetting will be done by choice, not necessity" (86, 2019). At this point in history, it is only possible to look back at what has taken place to try to move forward. In an effort to center Indigenous knowledge, Battiste (2000) spoke to elders who emphasized the importance of listening to "heart knowledge" and "blood memory". Heart Knowledge is based on your connection to identity, values, and relationships, while blood memory speaks to the importance of blood, family (genealogy) and inherited living memory. The concept of blood memory kept arising when working on this research. I had the sense that I was uncovering history, but also internalized memories, knowledge, and damage. Mithlo (2011) argues that the concept of blood memory blurs distinctions of racial identity, narrative and clarifies Indigenous wisdom expressed in verbal and visual arts. Any organization or community, such as Tribal museums, tribal colleges, and language-preservation offices are sites that encourage Indigenous people to draw from ancestral memories. It is also a concept that calls attention to the legacy of colonialism multigenerational effect $(106,2011)$. "This common tribal value of multigenerational remembrance runs directly counter to prevailing Western traits of individual achievement, lack of transgenerational memory, and transcendence of one's genealogical fate and place of origin” (Mithlo, 106, 2011). 


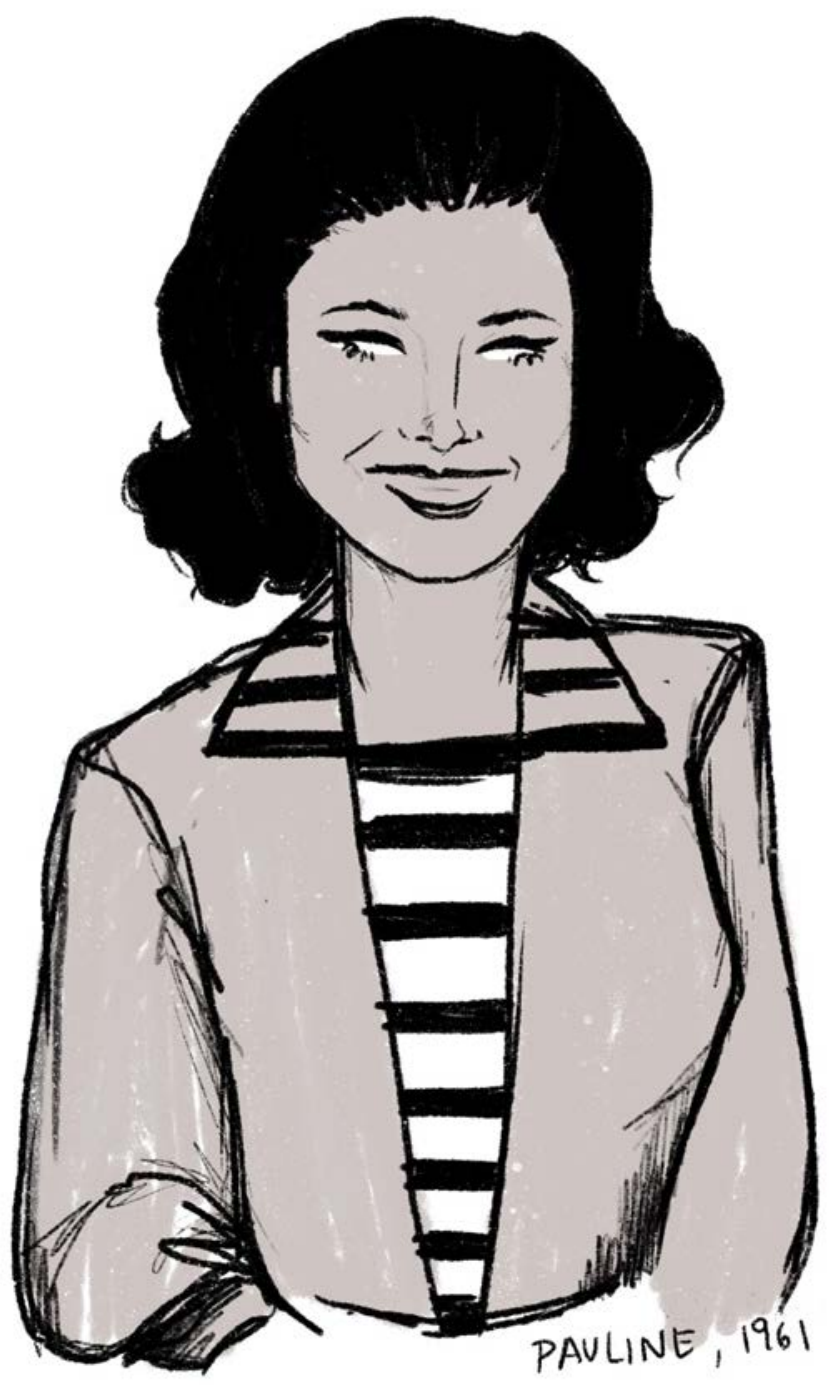

\section{Pauline's Story: \\ Reclamation, Reconciliation and Re-education}

Reclamation of Indigenous language, culture and identity is the first step of decolonization according to Laenui $(75,2007)$. Laenui identifies that the process of rediscovery and recovery also involves personal mourning and frustration, but also public debate and re-evaluation of our social system and structures. "The cohesion of an ancestral-based community is what gives medicine its effectiveness. Nevertheless, Aboriginal communities have adapted and developed restorative healing practices based on Aboriginal culture that are suited to modern-day concerns" (Laenui, 75, 2007). Interviewing Elders to specifically explore fashion and cultural identity acted as a restorative practice to collect and share knowledge but also helped inform a format for rediscovery that could be applied effectively to sharing other people's stories.

Next, I interviewed Pauline. Pauline was also 90 years old at the time of the interview. She was interested in fashion because of her grandma. She never got to know her grandma, but she knew her through the collection of photos she has of her. Her grandfather was Joe Healy, a Kainai man, adopted by whiskey trader John Healy of Healy/Hamilton in Fort Shaw Montana, after the death of his parents in an attack on his tribe. John was raised and educated to be one of the first Kainai (Blood) people to speak English in the area. As an adult, he became an interpreter and scout, but also a representative for Indigenous people. Joe and his wife Topitkinee (Pauline's grandmother), ended up travelling around North America for various functions because of his English speaking abilities. Pauline described them as dandies and very fashionable. They wanted to show off their unique Indigenous fashion, and because of this, they wore something new and 
different in almost every photo taken of them. Pauline thinks that her grandma had at least 12 dresses based on this photo collection.

Inspired by this, Pauline has developed a fashion show telling the story of traditional Blackfoot clothing by recreating the fashions worn by her grandma in the photographs. She has discovered, recreated, or reassembled fashions, starting with buckskins through to contemporary satin dresses. The fashion show is designed to explain each garment's historical context and traditional significance. She gave me a tour of her collection, starting by showing me a project she is in the process of beading. She showed me how she mockups up straight lines with a thread and how to stabilizes her work area with tape on each edge of the line. We went through her closet looking at details of each piece. They were colourful garments with intricate beading, geometric patterns, fringe, shells, and ribbon. She had also mixed in some pieces that could be considered western dress, such as house dresses in bright Seventies patterns. These were all clothing that she saw growing up. She pulled out a gorgeous wide-brim black hat with a beaded strap around the base and a vintage suitcase. The suitcase had a ceremony garment inside that included a heavy belt and a headband and moccasins with a bright red rose beaded on the top. She showed me each piece with love and care for the objects, explaining how they are worn and the names of the beads or how moccasins were laced. Her husband, a historian and writer on Indigenous people of the Great Plains, had encouraged her love for Blackfoot fashion years ago. I spoke to him to learn more about trading practices, the origins of certain materials, and making techniques. They were both a wealth of knowledge and she hopes her granddaughter will carry on her project.

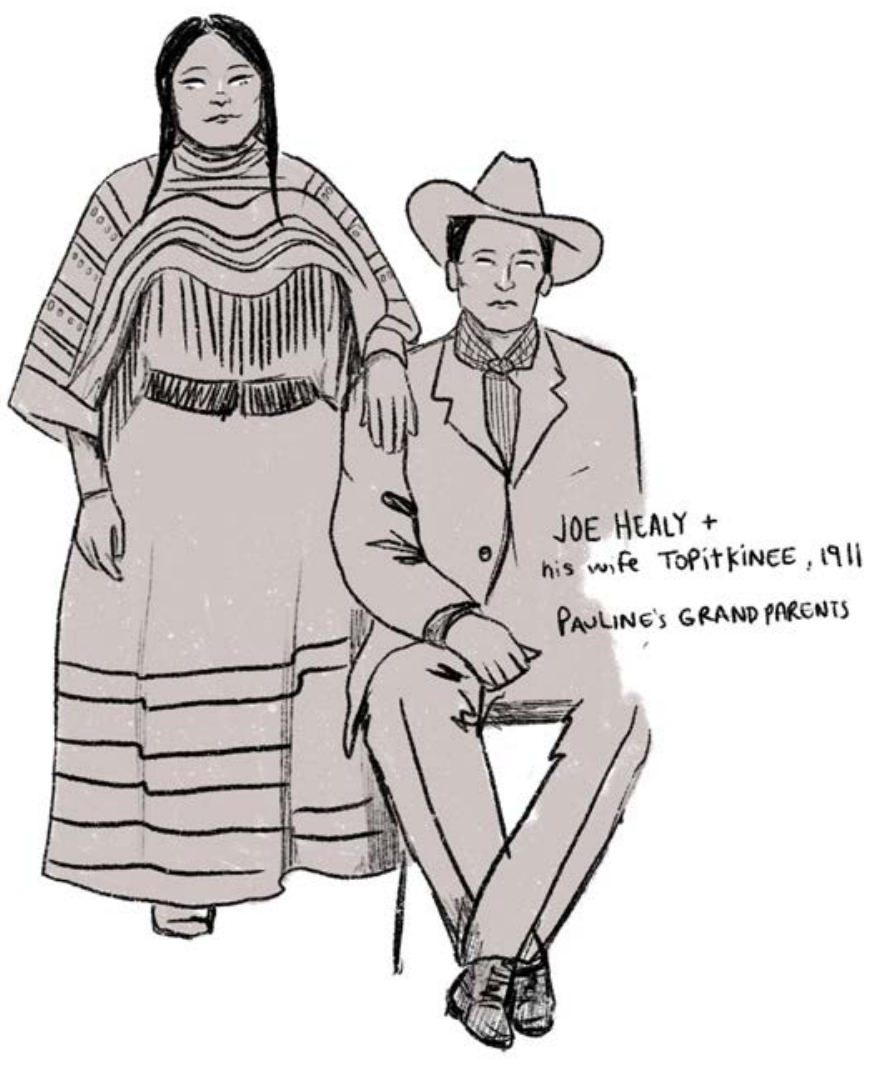




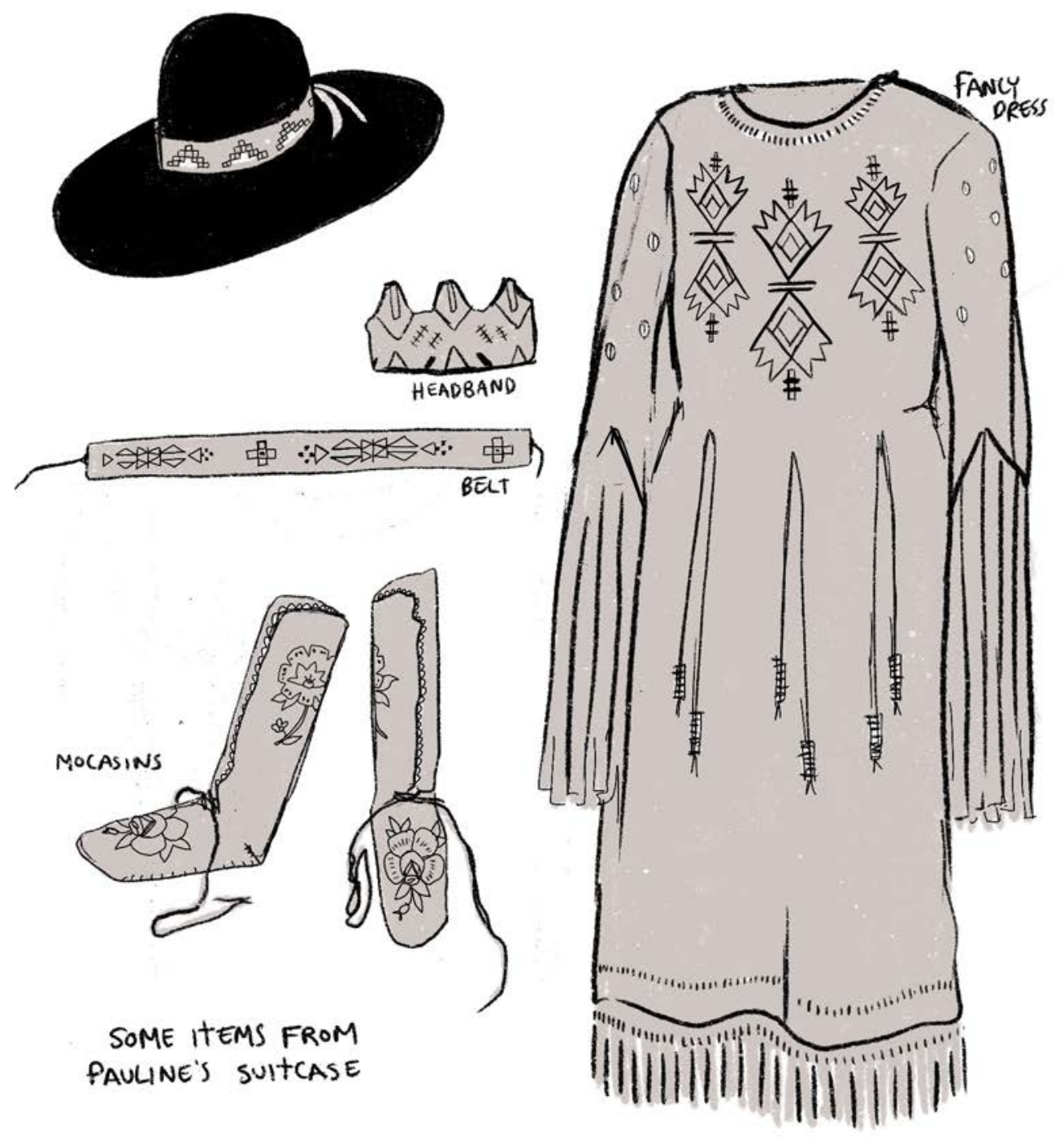

Pauline attended residential school but she maintained her pride in her Blackfoot/Blood culture. She was encouraged by her husband and family to embrace and share her culture and knowledge which has inspired her work to educate others. The work she is doing demonstrates reclamation and re-education of Indigenous knowledge and culture through fashion. She has made reclaiming Indigenous identity a crucial mission in her life. Sharing her story demonstrates how she not only overcame oppressive government practices, but she has made moves to encourage reconciliation by sharing her knowledge openly with others.

Pauline's interview demonstrated her efforts toward reconciliation and reforming relationships between colonized and colonizers. In 2008, the Truth and Reconciliation Commission (TRC) allowed areater portion of the population to publicly acknowledge the long-lasting effects of colonization and the mass violation of human rights perpetrated primarily by the Canadian government and the Church. The TRC is 
not indicting, charging, or convicting anyone in their report, it simply reveals and opens discussions about the violence, shame, and trauma surrounding the residential school system. The report provides the Truths that Canadians must all face but they can only provide suggestions of what Reconciliation can look like. That is why scholars such Flisfeder and Niezen are critical of reconciliation being possible in a colonial state. Flisfeder (2010) explains how the emphasis of the TRC is put on Truth and it treats "residential schools problems as an isolated issue, rather than taking a holistic approach"(1). This ignores Aboriginal teachings of how everything is related, and so reconciliation cannot happen until there is a bridge to share the wisdom of the past with the future and the residual, communal impacts of colonization are addressed (Flisfeder, 2010). In Truth and Indignation: Canada's Truth and Reconciliation Commission on Indian Residential Schools, Niezen (2017) is conducting an ongoing critique of the TRC and how it has knit testimonies together to produce a more favourable narrative for the Church and Government. The TRC is under the control of the colonial system of government, which then produces a version of Truth, especially by creating a narrative of a helpless unknown child abused by unnamed and faceless individuals. The Government is at a vulnerable position when moving toward reconciliation. Although the TRC is a form of acknowledgment of the suppression on Indigenous history, culture, identity through violent means, there has been far fewer efforts to address Reconciliation because colonial structure of power still have influence over individual and local interests. While Castellano, Archibald and DeGagné (2019) acknowledge that the heart of reconciliation is often understood as "spiritual renewal that carries with it an ethical obligation to take concrete action" (4). This means that decolonization can begin as a personal effort to unsettle existing social constructs, which Indigenous people can then carry out and implement to challenge the colonial state.

\section{Finding Common Language}

Galdys and Pauline's interviews told the stories of two wonderful, interesting Indigenous women and Elders. One told a story of assimilation. The other told a story of reclamation. Both interviews helped gain insight to Indigenous experience and I was overwhelmed by the complexity of retelling each story. They also revealed a gap between the academic and political understanding, and their personal understanding of decolonization. Decolonization is not conceptual or theoretical, it is a lived experience and is a reality or practice for Indigenous people. After all this, how do you explain decolonization?! 


\section{WTF is Decolonization}

Defining Decolonization is challenging and I see it as a fluid and transforming action. Decolonization was previously viewed as the process of taking back independence; the longterm process of divesting colonial power from bureaucratic, cultural, linguistic and psychological realm of life. Fighting for these major changes in a colonial system is very complicated and viewing decolonization as a personal process can make the goal of decolonization less daunting. Decolonization is about shifting how Indigenous people view themselves and how others view them, restoring culture, traditions, and language, and challenging policies designed for assimilation. Overall decolonization is about reclaiming control and independence, in whatever way each individual sees fit. Decolonization is often confused with Indigenization - which is defined as subject to native influence or to make indigenous. These are somewhat chicken-and-egg terms where there are some important distinctions. Indigenization is incorporating Indigenous ways of knowing and doing while it is recognized as a valid, equal and unique worldview (ICTinc, 2019). Using this paper as an example, my goal was to decolonize the research process, therefore, my research and creative decisions were a form of decolonization. The final execution of the research has been indigenized because it has incorporated Indigenous methods and epistemologies while being respected as a valid form of academic research within a Western system of education.

After reading more papers, books and articles than I can keep track of on the topic of decolonization, I still feel it can be complicated to understand. Especially when you try to discuss it with people who haven't invested hours into reading academic literature on the topic (which is most people). Living in Canada, I believe it is important to understand colonization or at least read the TRC reports or histories from Indigenous perspectives. The ' $\mathrm{rruth}^{\prime}$ part of North America's history is hard to hear, especially when the dominant narrative romanticizes the waves of pioneers creating a peaceful nation from the vast, untamed landscape. "The Aboriginal peoples of Canada-First Nations, Inuit, and Métis - tell different stories, of ancient origins preserved in legends, of migrations that spanned the continent, of trading networks and treaty making and sporadic conflicts to establish boundaries between nations, of prophecies that foretold how their lives would be changed by newcomers to their lands" (Brant, 1, 2019). 
Decolonization is a goal explored by many Indigenous scholars throughout the colonized world, with many of these concepts being developed in settler-colonial states like North American and Australia. The intersection of feminist, critical race theory, postmodernity, post-structuralist narrative theory and many other fields and frameworks problematized the Enlightenment paradigms of research and society. Decolonization is an anti-oppressive practice and the use of indigenous methodology repositions narratives, especially in settler-colonial states where there is no post-colonial state, but there is potential to affirm the existence and de-marginalize (Tuck \& Yang, 2012). Decolonization is a practice, not a metaphor. Tuck and Yang (2012) explain how metaphor can invade decolonization, which recenters settler narratives and resettles any indigenous methodologies. The word 'decolonize' cannot be grafted onto pre-exisiting frameworks or discourses related to other social justice causes. When indigenous people are excluded from the decolonization discussion, it re-settles the theory or discussion (Tuck \& Yang, 2, 2012). In Decolonizing Feminism: Challenging Connections between Settler Colonialism and Heteropatriarchy, Tuck (and others*, 2018) also discusses how liberal multicultural discourses assume minorities, different ethnic groups and women working towards inclusion and equality face the same issues and require the same types of solutions. This maintains settler colonialism when discussing feminism and race. But Indigenous communities concerns are unique, as these are often centred around the concept of independence from Western nation-states. Therefore, "within the context of land and settler colonialism, the issues facing Indigenous women, as inseparable from the issues facing Indigenous peoples as a whole, are resolved via decolonization and sovereignty, not (just) parity” (Arvin, Tuck, \& Morrill, 10, 2018).

An opportunity to "speak back to issues of racism, colonization and genocide" exists through the "context of contemporary Indigenous art” (Rivera-Santana, 2018). Aesthetic and material culture is an intellectual tool and can create authentic representations. Creative practices are an ideal medium for practicing decolonization that can be healing and collaborative. Clothing is a tool of self-presentation to create, maintain, challenge or modify social norms, expectations and expression. McNeill describes how researchers have established that an individual has the ability to identify them and others through clothing making it an instant visual signifier (McNeil, 82, 2008). Decolonization needs to take place in all aspect of society, but self-expression through clothing is an accessible outlet for decolonization, especially because clothing is a part of our daily lives. 


\section{Part 2: Making * Action}

\section{Methodology}

Indigenous research does not separate art, religion, daily experience from science. The assumption that research must be objective rather than subjective is broken down in Indigenous paradigm because all research has a motive and knowledge is relational (Wilson, 2008).

"Knowledge is shared with all creation" (Steibhauer, 2002), making interpersonal relationships important to Indigenous research. Many communities have been impacted by the colonization process by breaking apart connections to others and the environment/world/ideas (Wilson, 2008). The workshop design for my event, Fashioning Decolonization, is bringing together anyone who identifies as Aboriginal in Canada, which will create an environment where there is the shared impact of colonization but from varied perspectives to helps participants form relationships from varied Indigenous perspectives.

Relying on the methods of oral histories and fashion-based making practice has helped construct an activity design to explore decolonization as a tangible creative practice. Fashion is an ideal medium to explore complex ideas of decolonization because it is multidisciplinary and therefore allows for multiple theoretical approaches that present how "fashion takes shape, how it penetrates the world, reproduces itself and conditions the social and the power relations between individuals and society" (Riello, 2012). Self-fashioning provides an opportunity to explore and better understand decolonization as it is "a continual and processual affirmation of an individual's sense of self" (Birkbeck, 2014). Clothing empowers self-definition and provides individuals with the choice to maintain or modify how their self-identity aligns with social norms and behaviours (McNeill, 2008). This makes fashion a tool for decolonizing practices. Fashion is both an idea and an object, and it "reproduces itself and conditions the social and the power relations between individuals and society" (Riello, 2012). The embedded signifiers in fashion enter the spheres of politics, morals, economics, culture, sexuality and yet the individual must curate their own fashion within the complexity of what is communicated through them is carried and constantly changing (Baudrillard, 1993). Fashion can help construct an identity as well as challenge existing norms as a form of resistance. Just as Punk style was a rebellion against mainstream bourgeois culture, clothing aesthetics can counter gender, ethnic, religious, or socio-economic expectations (Barnard, 121, 1996). 
Fashion is the medium to apply the practice-based methodology, which also interacts naturally with Indigenous methods of storytelling, and oral traditions while treating research as ceremony. Using Tahera Aziz (2009) theory on practice-based research, the data communicated through arts practice can serve as a vehicle for systemic intellectual inquiry providing new knowledge and insights gained through the process of making (2009). Studies have shown that narrative practices can break linearity while being self-reflexive - which helps shift creative work into practice-based research. The activity design created a collaborative environment, where participants interacted with each other through discussion and collaborative making. Co-creation of art can intersect with co-creation of identity and while also helping to develop community. Researchers discuss how applying co-creation in creative projects, relying on social-constructivist traditions, helps develop a social identity, can strengthen community, and "can foster social change towards sustainability" (Calvo \& De Rosa, 2017). According to Angelique \& Mulvey “'lived” experiences (i.e., daily, ordinary activities and perceptions) are valued epistemological stances and critical ingredients for social change” (2012) which makes collaborative creative work a tool for design that is reflective of the community.

Wilson (2008) introduces in the book 'Research is Ceremony' that approaching research as a ceremony of maintaining accountability to indigenous relationships opens up new ways of knowing that exists outside the Western paradigm. The Enlightenment prioritized body/mind dualism which discredited "epistemologies grounded in process, practice and place". This also contributed to othering non-literate cultures by assuming that the world is a text. To understand it, it can only be read. This ignores embodied knowledge and 'means of creating, preserving and transmitting knowledge' (Taylor, 365, 2008) that exist outside the written form. Virginie Magnet (2012) describes how the central tensions for Indigenous people go beyond capitalism and neoliberalism version of democracy, they are rooted in the relationship between humans and nature making the central crisis spiritual. Wilson (2008) recognizes that "knowledge itself is held in the relationships and connections formed with the environment that surrounds us" (87). From this, research is ceremony because it relies on strengthening relationships with respect and reciprocity. Indigenous research is inclusive of multiple perspectives which encourages a form of epistemological egalitarianism (94).

\section{I designed a workshop called Fashioning Decolonization which treated research as a} collaborative creative ceremony, as described by Wilson, and combined fashion-hacking, storytelling, and practice-based research. I recruited participants who identified as Aboriginal, 


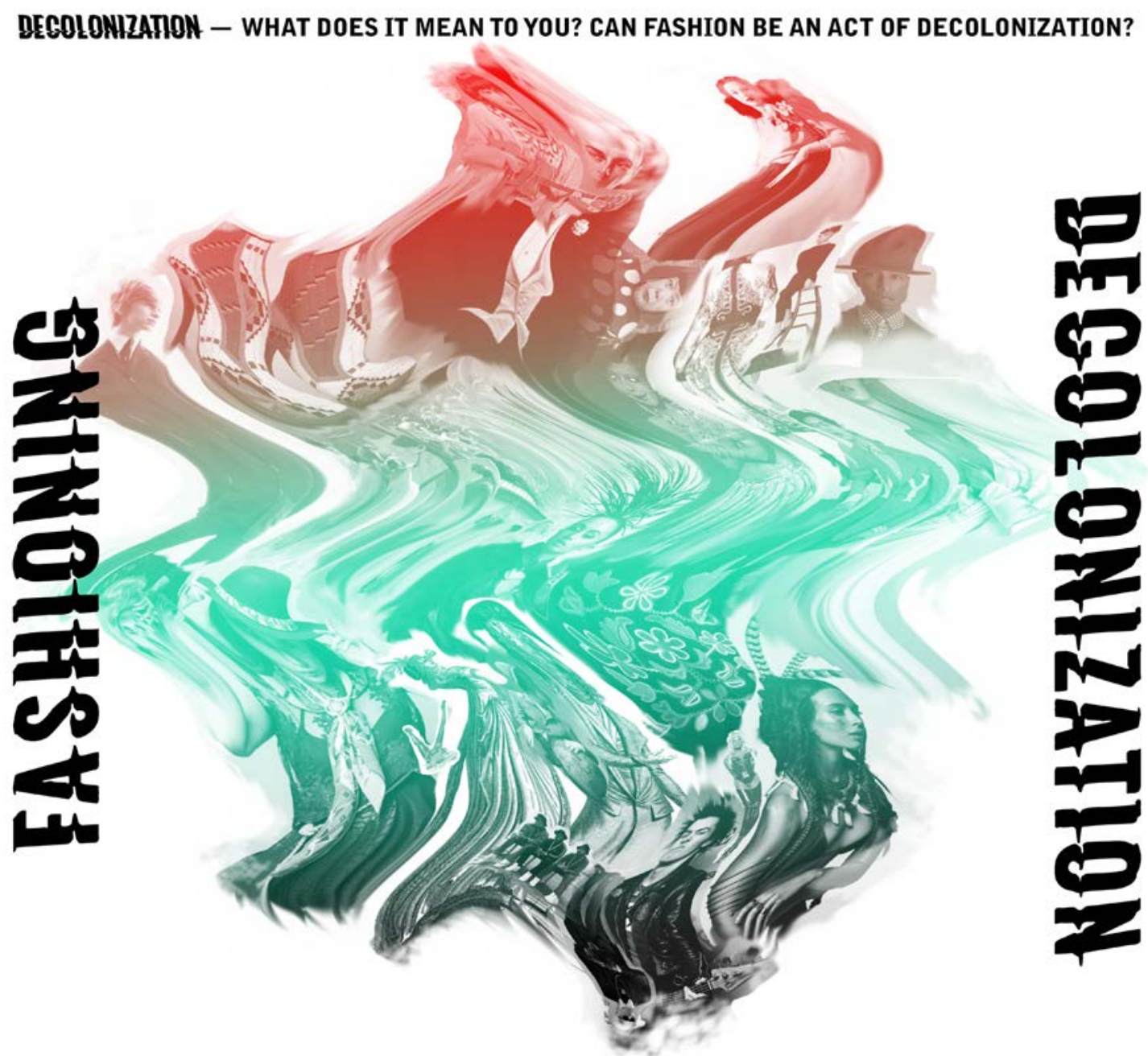

HELP US ANSWER THESE QUESTIONS IN A FASHION HAGKMG WORKSHOP

CONTACT PRESLEY.MILLS@RYERSON.CA

Appendix 1: Recruitment Materials

were over 18, and had any interest in fashion or art or decolonization. I hoped to attract a diverse selection of people to participate so that the research could share the experiences of a wide variety of people. To recruit participants, I designed a poster with the headline: Decolonization - What does it mean to you? Can fashion be an act of Decolonization? I hoped that the content of the poster would suggest that it would be a learning experience and participants did not need to come with any prior experience with decolonization or fashion. The poster was shared online through the Métis Nation of Ontario's email list, through Ryerson's Aboriginal Students Services on Facebook, and through my own personal connections. One participant was a family member and another participant was a friend and fellow Fashion Studies student. I called the event a Fashion 
Hacking Workshop. It was important to communicate that it would be a hacker or maker space because these bring up notions of open-access and equal participation (Hunsinger \& Schrock, 2016). The workshop was referred to as a 'Fashioning Decolonization - a Fashion Hacking Workshop' ${ }^{\prime}$ where participants will visually express decolonization.

The term hacking originated from the world of software programming, where programmers would reuse or share code to break-down and rebuild software to improve upon the existing systems. Hackers build things. They are commonly aligned with playful, constructive, and collaborative networks. The term 'hacking' can now be associated with do-it-yourself activities outside of software programming. Otto von Busch (2009) explains how hacking can be a constructive practice to subvert the traditionally hierarchical fashion system. Fashion-hacking methodology "features characteristics that could be of essential value when departing on participatory, engaged or sustainable fashion endeavours" $(163,2015)$ empowering change within the existing system of design and production. Although hacking is a wide practice some central points are that it grants greater access to technology or knowledge, it can empower users, decentralize control, create beauty and exceed limitations. There is an element of 'quick and dirty' making, but hacking can also be about craftsmanship and skill sharing. When applying hacking to fashion, such as in the workshop, taking existing fashion to deconstruct or upcycle 'puts a focus on postproduction processes, which could be open to people outside the fashion system, the usually 'passive' consumer (Otto von Busch, 170, 2015). Busch explores the example of fashion hacking with Giana Gonzalez' Hacking-Couture workshop where they decoded the 'source code' of existing brands to build upon brand 'codes' (2015), making new clothings that used the same language of 'high-fashion' companies.

Organizing the workshop, my goal was to create a community space that would encourage building connections amongst the participants. I arranged the studio space into one large table that the participants would circle around to work. Having them work at the same table encouraged open discussion and collaborative work. Each participant was encouraged to bring an item that they could deconstruct. Beyond that, there were no directions on what type of item to bring or how they would be deconstructing it. An 'inspiration bowl' was the only place participants could seek guidance for their creative direction. I created cue cards with examples of different making techniques and topics of inspiration. The cards contained design principles 
such as contrast, symmetry or repetition; other cards had hand construction techniques such as shredding, mending, or smocking. I also included cards with topics to explore such as reconciliation, gender, independence or narrative (list of cards can be view in Appendix 2). I chose to provide little guidance to leave the process open to the individual and encourage the spirit of hacking. After the initial interviews with Gladys and Pauline exposed a lack of clarity when it came to decolonization, I recognized how fashion-hacking employed with respect, reciprocity, and relationality could encourage collaborative discussion of lived experiences to better understand decolonization. The goal of the research was to gain an understanding of the gap between personal and academic/political definitions and to center their personal experiences related to the topic. The important aspect of the hackathon was for them to try making something new while surrounded by others in a supportive environment. The goal was not to learn definitions, bring up academic concepts, or try to come to a conclusive definition of decolonization.

After recruiting a small group of participants, we gathered in a studio for an afternoon of making. The topic of decolonization is heavy and complex, but I wanted to create a fun and relaxed space where strangers would feel comfortable opening up with each other. In my experience, as an introvert and maker, having an activity is a great catalyst for discussion. I introduced the workshop by sharing my reasoning for selecting this topic of research, followed by everyone introducing themselves and explaining what garment(s) they brought with them. I provided a variety of art and sewing supplies (such as embroidery thread, beads, scrap fabric, duct tape, paints, and markers) and after the introductions, I set them loose. Everyone started working without much hesitation.

The concept of deconstructing an existing garment was inspired by mending practices such as kintsugi ceramics and boro hand sewing, whereby repairing, remaking, and reassembling the object reestablishes value and the embedded knowledge becomes richer (Keulemans, 2016). Using an existing garment also naturally explores ideas of sustainability, as it is giving new life to something that would otherwise be forgotten or discarded. The idea of sustainability is especially relevant because most of the items brought were produced through the Western industrial production system. The workshop allowed participants to explore ideas 
around oral history and knowing-through making. They were able to demonstrate how shared knowledge is constantly reinterpreted through time and individual experience and how oral research methods can be used in a collaborative way to create an arts-based project (Smith, 2002) simply by participating. Having Indigenous people reimagine the garment was a way to indigenize it and reused clothing in a productive way.

Though earlier in this paper Tuck and Yang (2012) explain when decolonization becomes a metaphor it becomes re-colonized, ironically a few participants interpreted the garment created in the workshop as a metaphor. The decisions they made to reconstruct their clothing item did reflect their concerns or thinking on decolonization. My interpretation of this contradiction is that decolonization was a new concept for them, but makers of creative arts-based work are more comfortable making decisions that enter the realm of metaphor or semiotic interpretations. In that sense, the decisions made in the creative process could be metaphorical in nature but the outcome was still reflective of their lived experience and embodied knowledge.

After we reached the end of the available time, we went around the room to discuss the work each person had created. I asked, "What were you thinking while creating this and how does it relate to decolonization for you?" Each person brought up a unique interpretation and topic to explore. Some of the ideas mentioned were: reclaiming identity, sisterhood, relationship with nature, multiple identities, childhood, making as therapy, reinstilling purpose, and storytelling. Their stories will be explored in a series of short case studies analyzing their garment and their written response. The responses were written post-activity and before I shared a selection of readings, definitions, and examples related to Decolonization with them. (See Appendix 4)

In the book A Recognition of Being by Kim Anderson, she used the following statement "In trying to walk the traditional path there are four lifelong questions we ask ourselves: Who am I? In order to answer that I have to know: Where have I come from? And once I know where I have come from, I have to know: Where am I going? And once I know where I am going, I need to know: What is my responsibility? We ask ourselves these questions and every time we think we know that answer to one, it changes all the others." - Sylvia Maracle (16) 


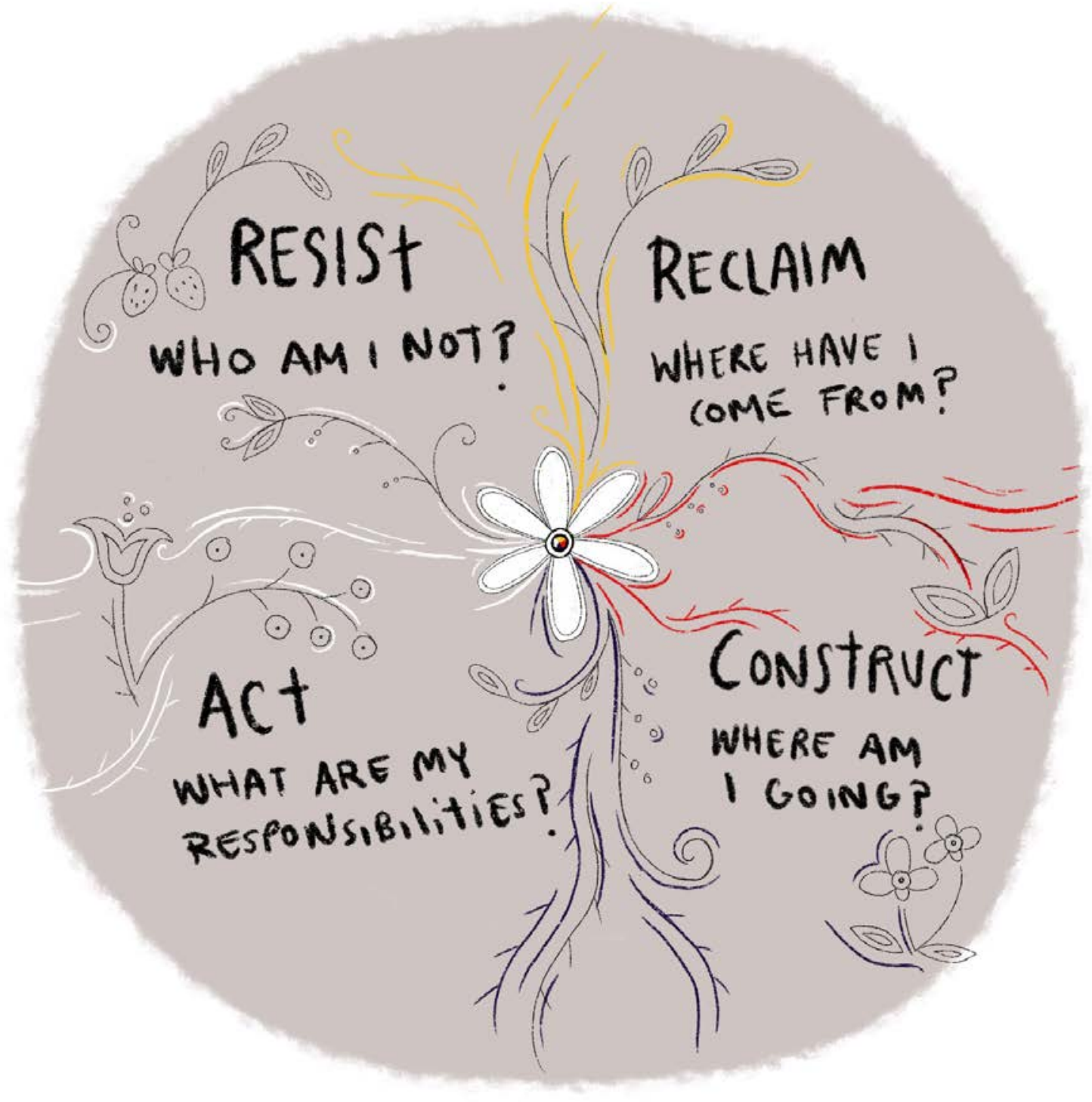

This statement by Maracle was used by Kim Anderson (2000) to create this wheel that illustrates the actions and questions we need to explore in the process of reconstructing Native womanhood. This diagram breaks down the complex questions brought up when an individual is thinking about decolonization. Kim proposes that Native women need to engage in self-definition to regain their power in spite of oppression. These are broken down into resisting negative definitions of being, reclaiming Aboriginal traditions, constructing positive identity, and acting on their identity in a way that nourishes the well-being of the community (15). The Fashioning Decolonization workshop design is not about coming to any final conclusions but is more so about sharing stories that reveal more questions. This format is distinctly Aboriginal as the past, present and future are understood as inextricably linked (Anderson, 2000). This wheel is the perfect format for demonstrating the cyclical nature of the questions and how they can be applied to an individual. This wheel will be the framework for exploring each case study. 


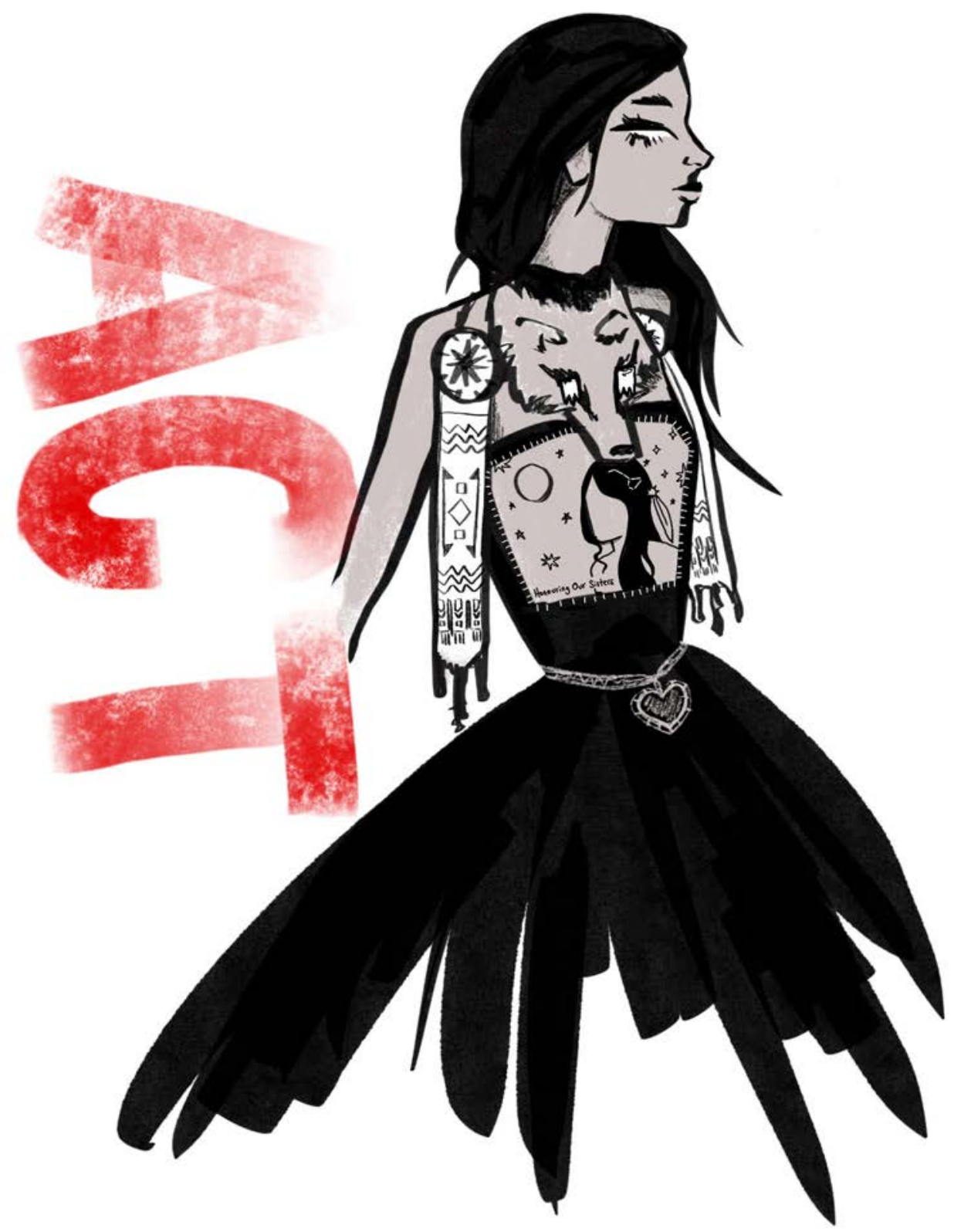

\section{Sarena}

Sarena is Lenape, Anishinaabe and Cree Metis woman from Toronto. She discovered the workshop through Ryerson sharing the event. She is currently studying Urban Indigenous Education, so she came with a strong grasp on her personal understanding of decolonization. Sarena brought with her a bridesmaid dress that she had to wear for a Catholic wedding ceremony. She also brought many smaller items to incorporate that have a strong connection to her indigenous identity, but they were stand-alone objects that could potentially find a home within her finished piece. She ended up using a graphic t-shirt, a scrap of black fabric, a coyote head, thread, two necklace pendants and beaded mink fur that her Aunt had made. The dress was transformed through embellishing the blank canvas. 
The dress was a bridesmaid dress el was required to wear to a Catholic wedding. elt's very structured and formal, and in a way represents the prescribed limits of Endigenous women in a patriarchal colonial system.

el had art from Elder Catherine Tamaro sewn onto it. This was art she created for Walking With Our Sisters, a large scale art installation and ceremonial bundle that travelled for seven years throughout Turtle elsland, honouring the spirits of the Missing and Murdered Endigenous Women, Girls, and Two-Spirit People. El was fortunate to volunteer for that project, and wanted to celebrate the art Catherine created for the project beyond just keeping the t-shirt in a drawer. The dress is floor length, ceremonial length, and el noticed the bottom of the skirt is dirty. I chose to keep that dirt there to illustrate the connection to the earth and resist societal judgements of perfection for women. I used the coyote face to put a face to the furs that are mass produced and worn without intention, but mostly to acknowledge coyote as one form of a sacred Trickster spirit in Endigenous cultures. I remember my Lenape Grandmother, Marion Johnson, reading me Nanabush stories as a child, so Trickster is very dear to me. The wise fool and teacher. There is one story where coyote loses his eyes so el am having my own extracted teeth put on the pelt to give him eyes.

The winter time is the time to tell these stories, as Trickster can be very dangerous too. Il connect Trickster to sacred knowledge that was demonized by imposing religious structures, similarly to elndigenous women. Il put a deer on the coyote's forehead, as those teachings, and our women, have been constructed to be viewed as prey throughout colonization. A current example is in the communities where pipelines are being constructed and all male worker camps attack endigenous women and girls. Often when bodies of murdered Endigenous women are found, they are 
so decomposed that only dental records are able to confirm their identities, which is why el chose to use my own teeth. Il also included some mink braid wraps that were my Aunt Marlene Finn's when she first started dancing. Il wanted to include a family connection to the piece since we do have family that were missing and murdered. Il also braided yarn to make a small belt - representing myself being one of three sisters and linking to the Walking With Our Sisters project. From this, Il hung a heart of coral, turquoise and lapiz, sacred stones in the shape of love. Which is what has been denied for endigenous women in the colonial construction of what has become Canada. For me, decolonization is identifying and healing those parts of our beliefs, that come from these external systems, that prevent us from being able to fully love ourselves.

Sarena came to the workshop prepared, with materials and a vision. She also came with the most wisdom and experience to share with the group. From her creative statement, decolonization is about honouring where she came from, and identifying and healing the external systems that prevent us from honouring ourselves. The work Sarena produced is highly conceptual and political, reflecting Act - What are my responsibilities? Activism and education are crucial parts of the garment. The focal point of the dress is on the Walking With Our Sisters t-shirt graphic and the coyote. Her activism for Missing and Murdered Indigenous Women, Girls and Two-Spirit people is displayed proudly on the front of her dress encouraging visibility. The coyote is presented around the neck. The coyote is a central figure in Aboriginal storytelling designed to teach life lessons. The details she included, such as her own teeth in the eyes of the coyote, make deep connections between her own experience and experience of other indigenous women. Sarena is considering her responsibilities to support causes that have impacted her and most Aboriginal people in Canada. She is also sharing and helping to inform others on the story of the coyote, the fragility of women under a colonial state and the importance family connections. This is expressed through the inclusion of many personal items to add to the dress, which enabled her to transform the garment without deconstructing it. 


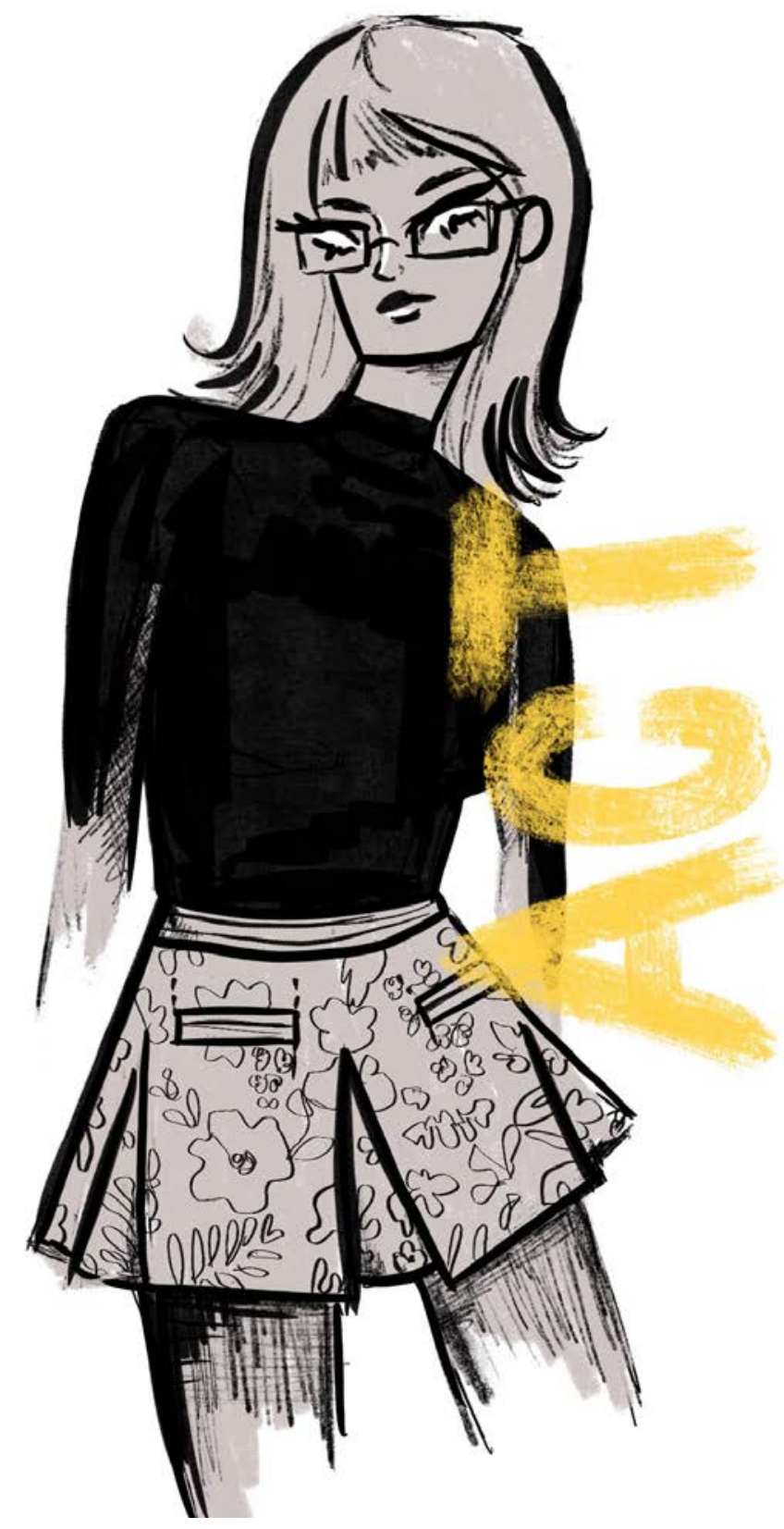

\section{Charlene}

I invited Charlene to participate in the workshop. She is my second cousin and a retired high-school sewing teacher who now lives in the southern Ontario. She grew up in Alberta and still has a strong connection to the outdoors, especially the North. Charlene is a very knowledgeable maker who valued function when deconstructing her garment. She came in with the intent to transform a pair of floral pants. The pants were made with colourful fabric that she liked, but she never wore them because the pockets were just for show. This impeded their function and she wanted to find a way to make the pockets useful. She landed on the idea to make them into a tool-belt/skirt. The bottom half of the legs were moved up to construct the inner pocket lining. 
Decolonization takes on a metaphorical sense in this project. Originally, a lightweight denim pant with an elastic waist and faux pockets, the garment was never satisfactory in fit or style. This was an attempt on the part of the manufacturer to create a one size fits many with the illusion of comfort and some style detail. Decolonization represents a return to authenticity, a return to meaning and purpose. The pocket welts on the front and back of the pants were well-constructed. But there were no pockets. The elastic waistband was poorly situated and did not match the weight of the pant fabric. Aesthetically, the blue elastic was pretty in texture and colour and complimented the corall pinklbluel white floral pattern on the pants. The pants were pretty but hardly functional and therefore lacked purpose.

In an effort to return purpose to this garment, the first step was to create four functional pockets by opening the welts and attaching a pocket bag to each welt from the interion of the garment. This was created with part of the pant legs which had been trimmed to upper-thigh length. With the remaining pant fabric, four box pleats were created and sewn into the side and front/back seams to create skirt ease. The waist elastic was retained because it now allows the wearer to slip it easily over another garment. This new purposeful 'skirt' can now be worn as a garden apron or a craft tod apron. The four functioning pockets will work well for this. As a maker. every project from my studio must exist with function. Necoration does not interfere with function. If there are buttons, there is a buttonhole. If there is a tie, it is securing something. A zipper must unzip. Beadwork, lace, or trim of any sort must accentuate a necessary aspect of design. Authenticity is important in cultural statements. At is vital to longevity. At is vital to loyalty.

The very first sentence of her creative response contradicts Tuck and Yang, but for her decolonization became a metaphor for function. The pockets on her pants were just for show. 
In the group discussion, we related this to how there are many symbolic efforts made to look like decolonization, but often they have no impact of the lives of indigenous people. Throughout the workshop she spoke about her connection with the environment and how we must treat it with more respect and care. Her garment reflects Act - What are my responsibilities? because she strongly considered the garment's participation in her life and as a result created something that will now be used to help her garden. She came to the workshop with a rough understanding of decolonization, but I think she was unclear with how it could be practiced. Her desire for functionality can be applied to how she thinks about Indigenous knowledge and practices. As a family member, we have a shared history of growing up detached from our Indigenous culture. She was a source of a lot of new information for me as she grew up in Northern Alberta with more family around her, but she hasn't gone through the same process of reclaiming Indigenous knowledge. Her work demonstrates a desire for practical real-life applications of decolonization. She recognizes the value of it and for her, it has the greatest impact when decolonization relates to the land. 


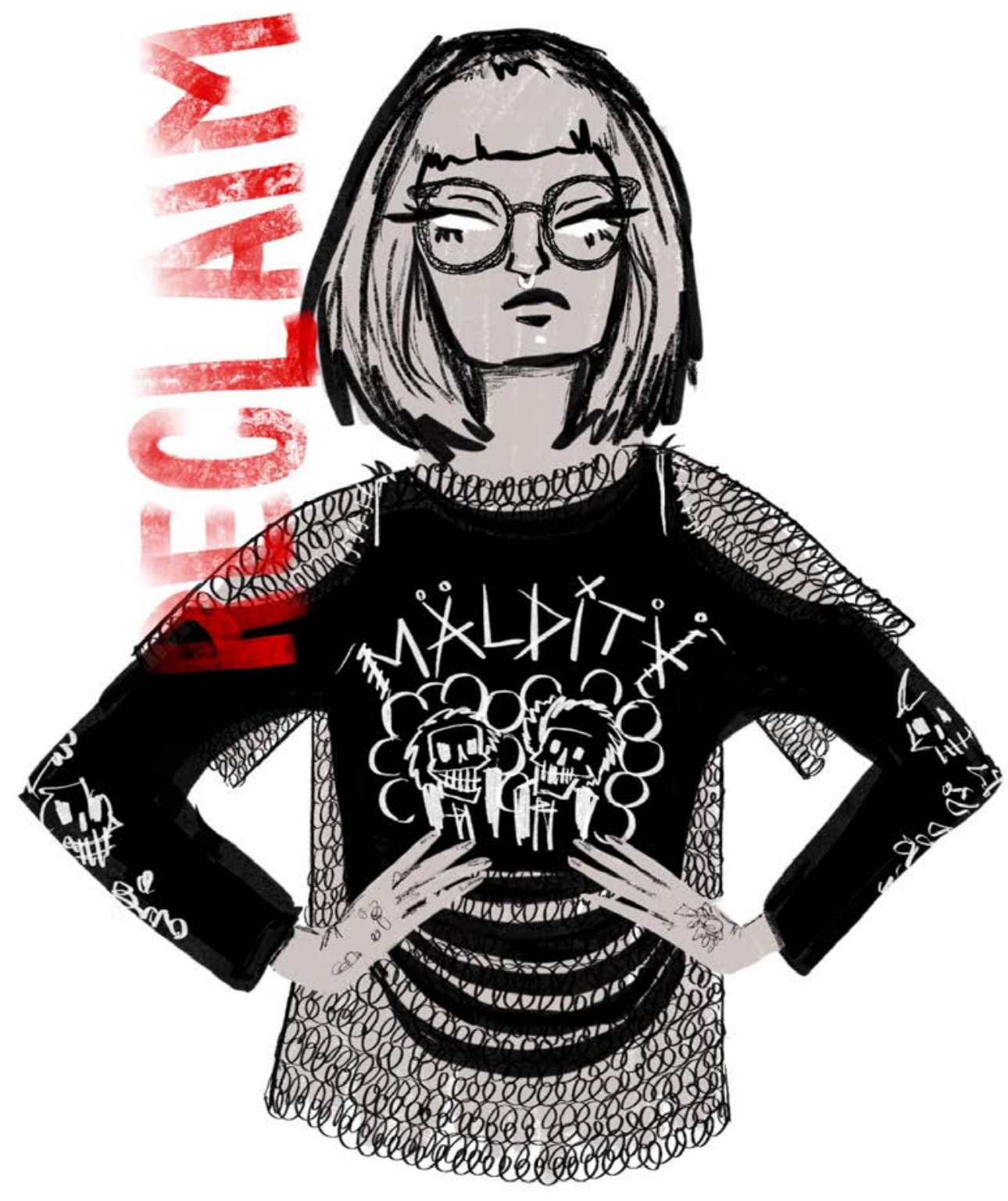

\section{Alysia}

Alysia is a friend and fellow classmate, as well as an accomplished designer. When I began talking about my research with her, she revealed to me a similar experience of the challenges confronting Métis people. She has recently begun the process of looking into her indigenous identity further. She is non-status Métis from Nova Scotia and acknowledged that her family express shame and disinterest in connecting with their Indigenous background. Alysia brought two shirts with her to the workshop and wanted to find a way to combine the two together. The first shirt was a band t-shirt and the second was a long sleeve mesh shirt. During the workshop she cut and ripped the fabric and stitched new elements together to create a new punk-looking shirt. 
This piece ties together two different shirts. One shirt is a band tee from a friends band whose roots are based in Peruvian Political punk music. The other shirt is a cheap fishnet top that a bought at a store in the mall (Sirens). The shirts combine together many oppositional qualities: long sleeve \& short sleeve, opaque \& transparent, cheap + meaningful. They both are ill-fitting and uncomfortable because of their size and material and shape/silhouette. The shirts mash together these identities as a reflection of my own conflicting identities - Endigenous * French colonizer, academic * punk, femme and not so much. Decolonization, to me, manifested through this garment as a co-existence, sharing and mending the torn relationships If have to my own indigeneity.

Alysia's work brought up identity more than any other participant. When discussing her work, she brought up her personal exploration of expressing multiple identities and mending her personal connection to being Métis. Hers was also the second political t-shirt to be transformed in this workshop along with Sarena using the 'Walking with Our Sister' t-shirt. These graphic t-shirts successfully communicate a message, but also demonstrate how a simple mass-produced t-shirt can become a strong signifier for resistance or an expression of identity. Using Anderson's (2000) framework, Alysia reflects Reclaim - Where have I come from? as she is in the process of researching her own history and overcoming her family's lack of connection. She is choosing to identify herself as Métis, academic, punk, femme (sort of) and these multiple identities are her path of resistance to help her develop a positive Native female identity. 


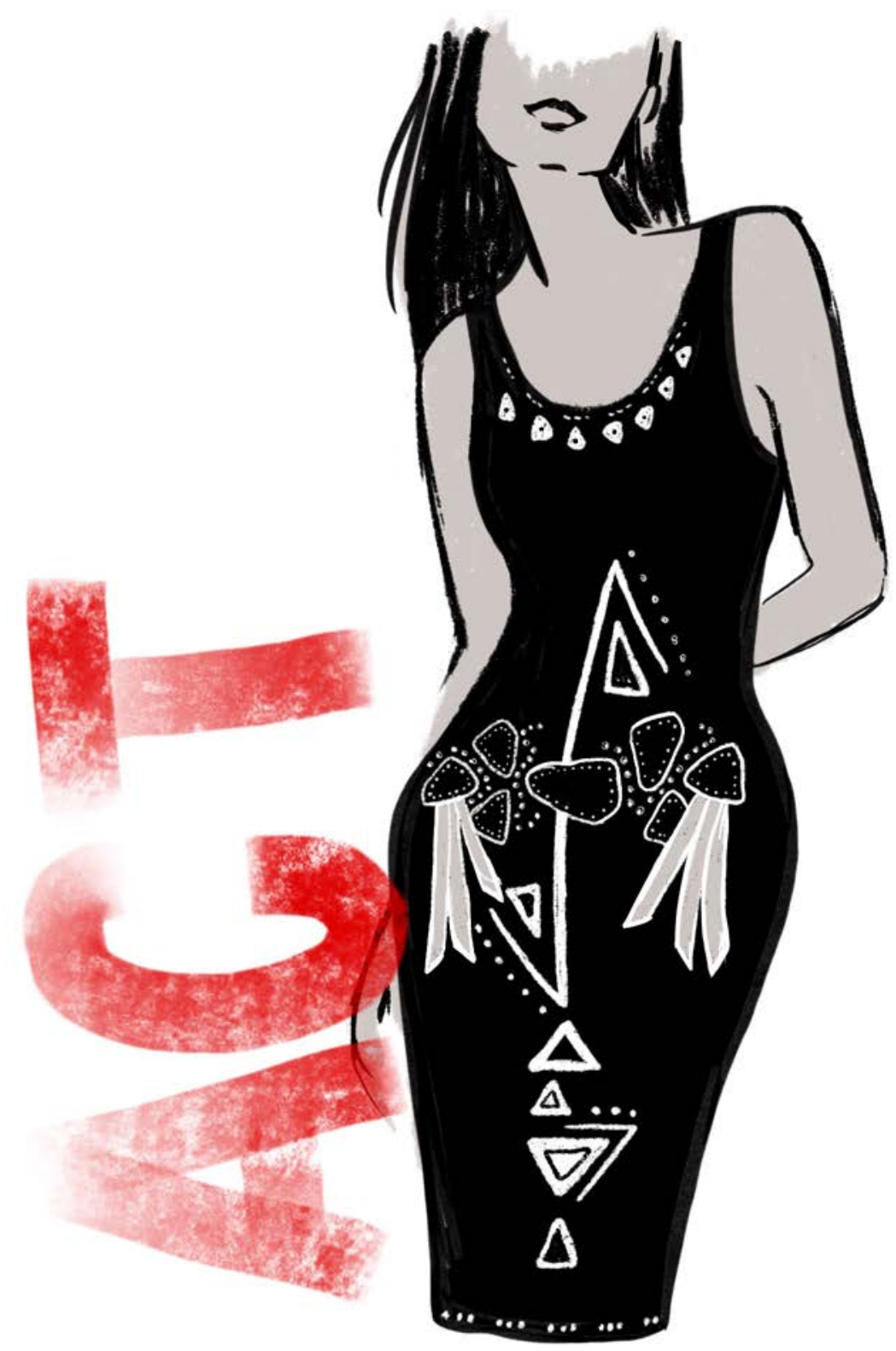

\section{Alexandria}

Alexandria is 0jibway and works as a holistic health \& wellness practitioner. She came to the workshop through one of the online postings. Alex came to the workshop with her sister in mind. She said when she saw my recruitment posters that it was the perfect activity for her sister, Destiny, and her to do together. She brought a black stretchy dress with her to the workshop and started by trying to bead around the collar. It was her first time beading so she quickly realized how time consuming it is and switch over to painting on the dress. She painted patterns and strawberries, covered them up and repainted new patterns. Her painting made reference to petroglyphs and used the colours of the medicine wheel. 
She fell into the process of exploring the material after being hesitant and unsure of what she wanted the final piece to be. During the group discussion, she revealed that she is not comfortable creating in this format. Her primary outlet for expressing herself is through cooking as a holistic nutritionist who runs the catering service The Wholesome Conscious. She discussed how food was her personal medium for decolonization and healing. Coming to the workshop related to Act - What are my responsibilities? Alex is actively engaging with the idea of decolonization daily through her diet, cooking business, and dance. She is also acting on her Indigenous identity to consider her responsibilities beyond herself. She participated in the workshop as a way to support and build up her sister and her sister's creative skills. Even when introducing herself, she spoke of how important and talented her sister is. She demonstrated a strong sense of who she is and used that confidence to build up others. During the closing discussion, she explained transforming the garment was very challenging for her but through the process, she recognized that she is more creative than she gives herself credit for. Her journey in this process revealed two things, that supporting others can heal oneself and that all forms of creativity, whether it is food or clothing, can be therapeutic.

Alexandria's piece is in remembrance of our missing and murdered endigenous women. The triangles represent the communities that hold the red ribbon, never forgetting those sisters, aunties, mothers, cousins, etc. And the red ribbon represents the long history of how our MMNW have been minimized within the public eye.

The dress she made is embellished with brown suede patches, ribbons on the hips, painted petroglyph-style patterns, and beading around the collar and patches. I received this informal creative statement via her sister after they took the garment home to complete the beading. Based on comments they made during the workshop and how her sister was the one teaching her beading techniques, I can assume Alex had her sister and mother support her in the beading process. Alexandria's creative decisions align with Act and how she actively engages with her responsibilities to her community. I chose to include the words of her sister as her statement because it shows how they empowered and support each other. 


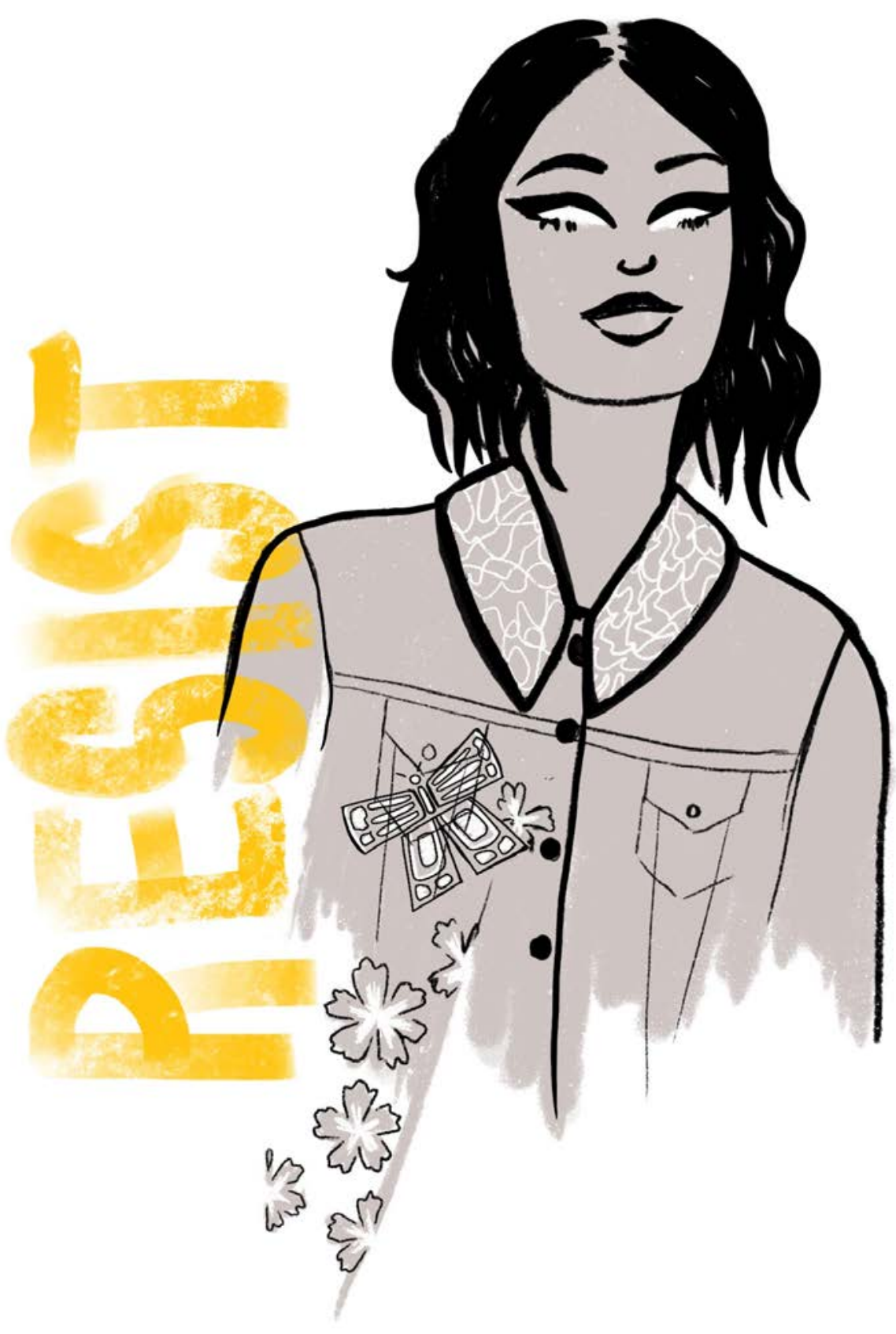

\section{Destiny}

Destiny came with her sister Alexandria. She is someone who has experience in a variety of arts practices, and her sister Alexandria spoke about how she is the most creative person she knows. Destiny brought a hand-sewn soft-pink jacket and a denim jacket, but decided to just work on the denim jacket. Using sheer pink fabric provided, she began making rosette appliqués around the collar. Though she ran out of time, her intention was to fill the collar with the rosette appliqués to create a super feminine and dramatic look. 
el decided to embellish a jean jacket ... in terms of decolonization it's an interesting choice as denim originally stems from Europe. Nuring the process el tried to be as free as possible. I wanted my intuition to carry me through it. The collar happened by mistake as el was originally trying to create flowers but the happy accident yielded a very whimsical effect that's reminiscent of pink clouds or cotton candy and it inspired me to continue in that direction. So the theme became 'inner child'... Il pulled on my preferences as a child from the little mermaid on the back, to the flowers and overall girly pink feel. Il added a woodland style butterfly to honour, not only my Qjibway roots, but it also symbolizes transformation in this cave el see it as transmutation. Overall approaching from my child perspective el believe is the embodiment of decolonization. A type of deprogramming of what's been imposed and tapping into intuition magic whimsy and what my soul calls to.

Destiny was soft-spoken but obviously was very close to her sister as they spent the workshop joking and discussing what they should do with their garments. In the discussion, Destiny talked about how her personal expression of decolonization is about reclaiming who she was as a child. This relates to the Resist- Who am I not? as she explained how she has changed as she has grown up. As a kid, she would spend her time exploring the woods. She was curious, outgoing and fearless. Over the years she feels the world has made her more cautious and reserved. The word 'deprogramming' stand out in her creative statement. Her decolonization is reconnecting with her intuition and healing her soul. The creative process seemed to be an opportunity to consider the ways society has controlled her and to reach into her past to challenge that. She is thinking about re-awakening her true nature and resisting the oppression that has caused her to loose this connection.

Having sisters participate was a special contribution to the research. Alex recognized Destiny's need for resistance and chose to act upon this to support her. This really demonstrated the power of relationships to support and encourage healing. 


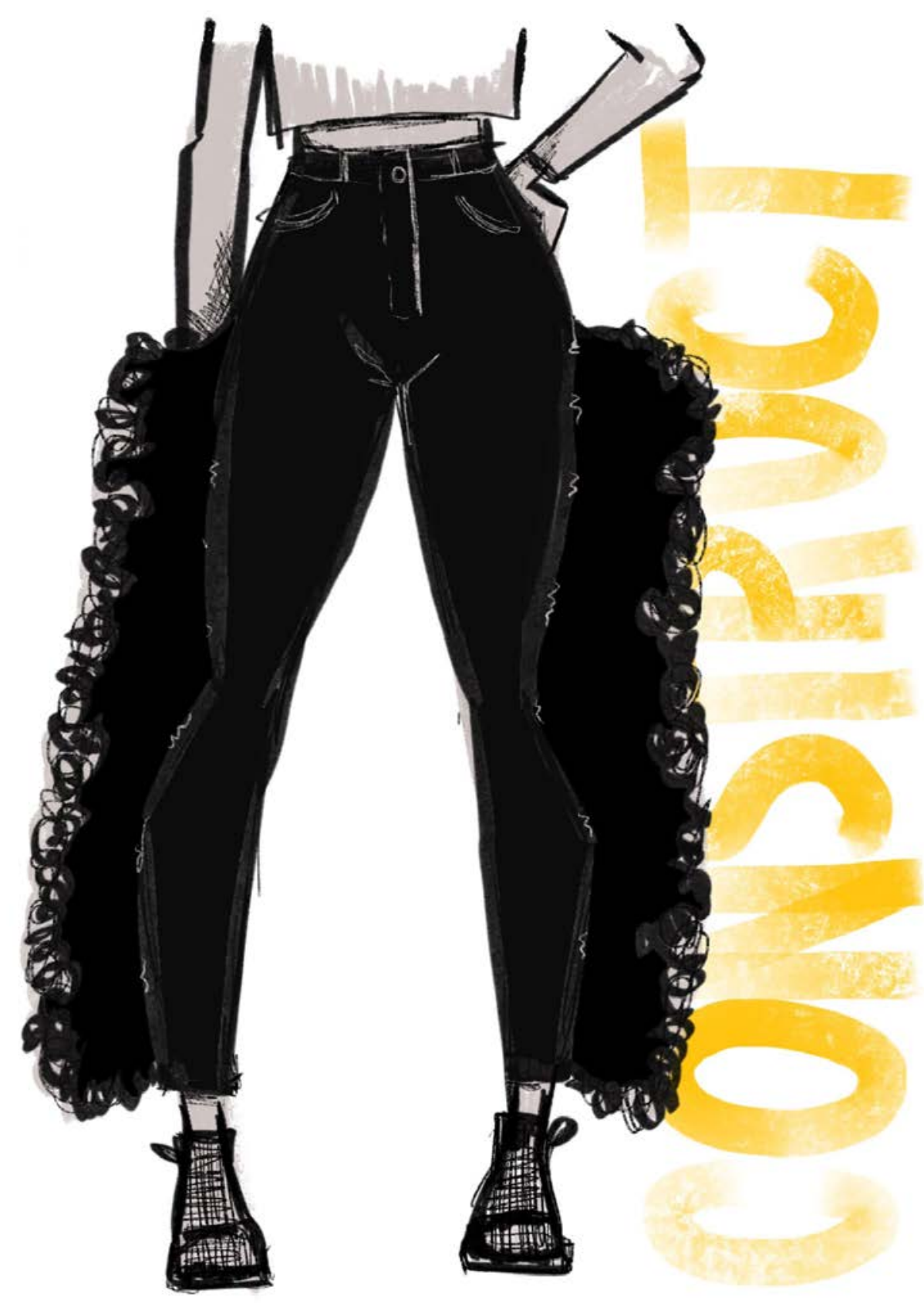

\section{Presley}

During the workshop, I planned to work on my own garment but also be available to support others in whatever capacity they needed. I ended up assisting people in their making process, therefore I wasn't able to transform a garment with them. I did plan to explore the whoopi pants concept because I thought it was an interesting continuation of the interview I had with Gladys. After the workshop I gave myself the chance to transform a pair of old stretch jeans into my own interpretation of whoopi pants. 
Since interviewing my great-aunt about her clothing, If have been thinking about the pants she described as jeans with fringe down the side. Or Whoopi pants. I decided to create my own interpretation of them using an old pair of my jeans and some Auffy fabric. Il was inspired by woollies, which are a type of horseback riding pants that cover the outside of your legs with long floppy wool for protection. Starting to consider decolonization was a learning process and about reclaiming stories and ways of life. What the process of making has added is the strength of community and collaborative work. Although ef wasn't able to work on these pants during the workshop, If was still able to work with the participants to help them realize their vision for their garment. If found the process of making with others inspiring and the workshop allowed me to her stories beyond my own experience. At this point, If think these pants reflect how If have embodied where If have come from and how et am moving forward.

The beginning of the research related to Reclaim - Where have I come from? I had to overcome hesitation around exploring the topic of my Indigenous identity because I was very disconnected. What encouraged me to continue was hearing diverse and unique struggles, in person and in writing. Many people I encountered had similar stories to my own or were beginning to practice decolonization in their daily lives. Decolonization began to manifest through researching where I came from, but it has transitioned to the Construct - Where am I going? as I come to the end of this research project. I don't have all the answers but I have found a way to express where I come from by embracing elements of western wear. It sounds funny, but coming to Ontario exaggerated my connection to where I grew up. I am now considering the Construct question as I move forward in my own decolonizing practices and how this research can potentially move forward. I also hope to continue to help share the voices of others as the process of storytelling had the more transformative effect on my understanding of decolonization. 


\section{Activity Design Reflection}

Based on the feedback in the participants' creative responses, the Fashioning Decolonization workshop was successful in expanding participants understanding of decolonization through creative practice.

The format helped fosters great discussion and collaboration throughout the entire three-hour work period. As this was the first attempt at the activity design, there were some limitations and challenges to address. The participants included were all women, which was not an original exception in the recruiting materials. Based on my observations, most of the participants had an existing understanding of the academic definitions of decolonization, even if it was limited. This could suggest that the name of the workshop could have been intimidating to participants without some background knowledge. The discussion during the workshop did support that being around other Indigenous people and hearing other people's stories did help expand their understanding of decolonization. The small group of participants did not reflect all of the different Aboriginal groups of Canada. In future iterations of the workshop, the activity could benefit from a more diverse group of participants who reflect a wider variety of ages, gender, races, and experiences that would provide even more diverse stories. The workshop could also benefit from slightly more time for constructing the garment. I allowed a few of the participants to bring their garments home to finish. Because of the time limit some crafts available to them, such as beading or embroidery, could not be completed during the allotted time. Limitations on certain techniques could be another solution to encourage participants to complete their garment within the time limit.

This workshop was limited to participants who identified as Aboriginal, but many people who are not Aboriginal have expressed interest in learning about decolonization through a fashionhacking workshop. I have one more story to share who demonstrates this interest and potential opportunity for practicing reconciliation. Jon was the outlier in the workshop. Jon is Charlene's husband. He was the only man who chose to participate and he does not identify as Indigenous. They live out of the Toronto area and chose to drive in together. Jon expressed interest in observing because he wanted to learn about decolonization. Once we got started, I offered Jon the garment I bought for myself; a pair of worn-out stretch jeans. He had no making experience but took the opportunity to participate seriously. Charlene and I gave him some making advice and helped thread his sewing needle, but he developed the concept and did the work himself. 
Jon transformed the jeans into a backpack by turning the bottom half of the legs into straps and the thigh/waist into the sack portion. Having one white man included in a group of Indigenous women was unexpected and I was unsure how he would be included in the research. His inclusion brought up some discussion of how fashion and making are typically gendered, making him hesitant to participate in fashion when he was younger. This topic brought us negative experience's Charlene had as a sewing teacher, receiving negative comments about the value of sewing skills by male co-workers. Jon was happy exploring sewing for the first time in a supportive environment. He strongly connects ideas of decolonization with the environment, similarly to his wife. He was a positive addition to the workshop and didn't 'take up space' intended for the Indigenous women. In this sense, I think his creation represents an ally. Jon didn't fully finish his creation but was open to me continuing it myself, however, I saw fit. Here is his creative statement:

\section{Jon}

Beginning with a pair of dark denim stretch jeans, the search for an interpretation of decolonization took some time. As a garment, jeans have been abstracted from the underclass world of hard physical labour to the ethereal and often purposeless world of high fashion. Economical sturdy cotton denim with hardy stitching and rivets worn only in fields, mines and on horseback is an expensive everyday wardrobe staple, prized far more for style and status than sturdiness. Repurposing this pair of spandex skinny jeans as a backpack seemed the best option. A backpack implies a journey. A backpack suggests a cache of belongings that are necessary to one's journey. This pair of jeans had functional pockets that would serve a backpack well. The legs were turned up and sewn to the waistband to form loops that would serve as straps. the top of the pant was turned to form a flap for closure. Once decided, the sewing became the struggle. Creating a backpack that would withstand the wear and tear of a journey took time. The concept of decolonization works here as the jeans and the backpack symbolize a journey. Exploring the land on foot, on horse, by canoe or kayak, camping and sourcing food on the land in each season acknowledges indigenous ways of life. 


\section{Moving Forward}

Learning about Indigenous history and thinking about how we can move forward after centuries of oppression and violence was challenging and overwhelming. Examining the past and the present is instructive - and as King (2012) states it shows that there is little shelter or gain from doing nothing so every pursuit of self-determination and sovereignty is of value. He says "Native cultures aren't static. They're dynamic, adaptive, and flexible and for many of us, the modern variations of older tribal traditions continue to provide order, satisfaction, identity, and value in our lives" (278). The first half of this paper is called Storytelling \& Discovery. Wilson describes three types of stories: sacred stories, Indigenous legends, and personal experiences (98). Throughout this research, there has been an emphasis on the importance of personal experience as storytelling to help counsel or teach. It began as a personal journey for myself to consider the questions that Anderson proposed while grappling with my Métis identity. The statement by of Anderson reflects my own experience entering this research:

\footnotetext{
"In the Native community, we struggle with our own version of the vanishing Indian. I think many of us feel insecure because we lack the knowledge that was ripped away from our ancestors. We have internalized the belief that we are "less" Native because we can't measure up to some kind of quintessential "Native experience" whereby we grow up on the land, speak our language and are well versed from an early age in Native ways." (Anderson, 26, 2000)
}

Interviewing the Elders in my home province opened up my understanding of the vast possibilities of "native experiences". Speaking to them helped me identify the gaps that were worth exploring and I believed could be engaged with through fashion and making. It was important to considered value and reciprocity when examining the research questions: What does lived experience of decolonization look and feel like for indigenous women? How do individuals think about decolonization in the personal aspects of their life and how can that be expressed through fashion? Can making fashion expand our understanding of decolonization? Can fashion-hacking be a decolonizing practice? 
Early on I realized that the concept of identity was not of value to those who have already answered Who am I not, and Where have I come from? outlined in Anderson's framework. To design an activity that would be of value to all participants it needed a framework that was inclusive of all Indigenous people's journey towards healing (whatever form that may take). Decolonization stood out as a topic of value and confusion during my initial conversations. Having these conversations contributed to my personal experience and these relationships reflect an elemental aspect of oral tradition (Wilson, 2008). The combination of oral tradition, collaborative creative process, an unconventional writing style, and illustrations help bridge some of the gaps that are generally missing in exclusively written text.

\section{How do individuals think about decolonization in the personal aspects of their life and how can that be expressed through fashion? Can making fashion expand our understanding of decolonization and can fashion- hacking be a decolonizing practice?}

The participants expressed through creative work, education, family, food, and fashion. The discussion during the workshop demonstrated the variety of ways an individual can practice decolonization. Every participant had their own unique way to challenge colonial powers that have had an impact on them. Whether that was participating in public demonstrations of activism or the food they choose to consume; their actions demonstrated how decolonization was about making choices to unsettle existing constructs. This workshop did reveal that not everyone understood how to begin decolonizing themselves. The discussion and shared stories did expand participants' knowledge and hopefully influenced each other's personal experiences to make intentional choices towards decolonization. Though the clothing was its own form of decolonization, the act of deconstruction and remaking clothing was most powerful as an instrument of discussion. The workshop became ceremony, as it fostered an environment of respect, reciprocity, and relationality.

\section{What does the lived experience of decolonization look and feel like for indigenous women?}

Based on the work created by the participants, I can only begin to answer what the lived experience of decolonization looks and feels like for Indigenous women. The participants 
highlighted reclamation, relationships, and identity as the major themes when considering personal decolonization practices. Reclamation meant a combination of learning about where they come from, the history of their ancestors and learning cultural practices that were lost because of colonization. It also meant learning to take pride and ownership of their heritage. The relationships in their lives informed what stage of Anderson's framework they were exploring: Resist, Reclaim, Act and Construct. Those with a community or a support systems who have begun the process of decolonization were able to consider the impact of decolonization in the greater community, whereas those beginning the journey of decolonization still had a personal question to consider. Although the term of identity was met with confusion early on in the research, I observed that the Elders I spoke to had a different relationship with the word compared to some of the younger women. I can assume that this relates back to Logan's (2019) statement about how in an open environment, active remembering or active forgetting is done by choice. Young people now have the choice to try to activity remember and inform themselves, making personal identity a valuable question and choice to consider. As someone who is only beginning the complex process to decolonization and learning Indigenous epistemologies, this question of identity between generations could benefit from further consideration.

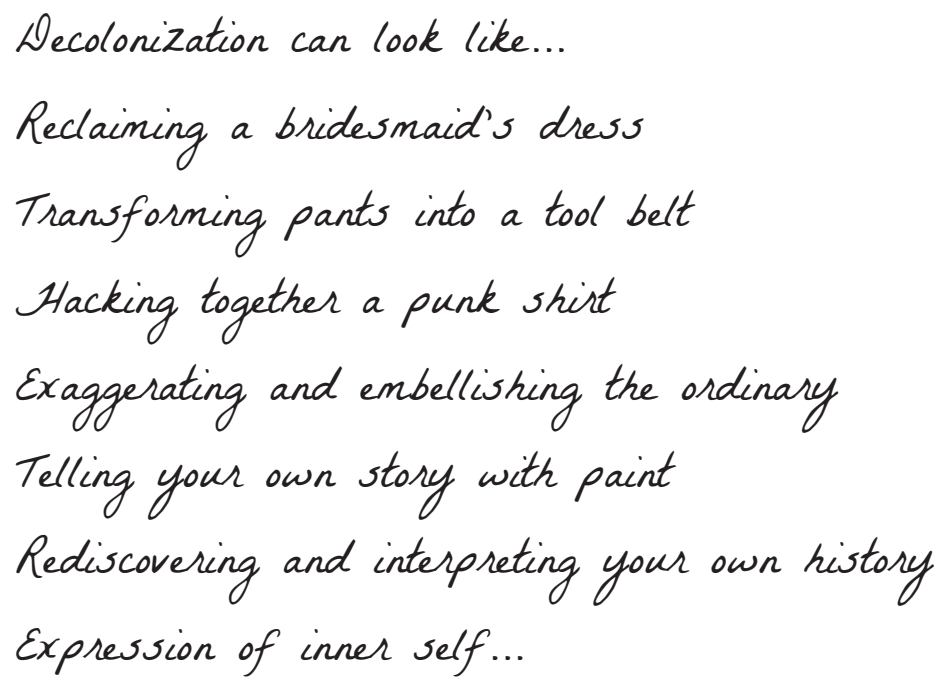


Fashioning Decolonization: Mills

This page was intentionally left blank. 


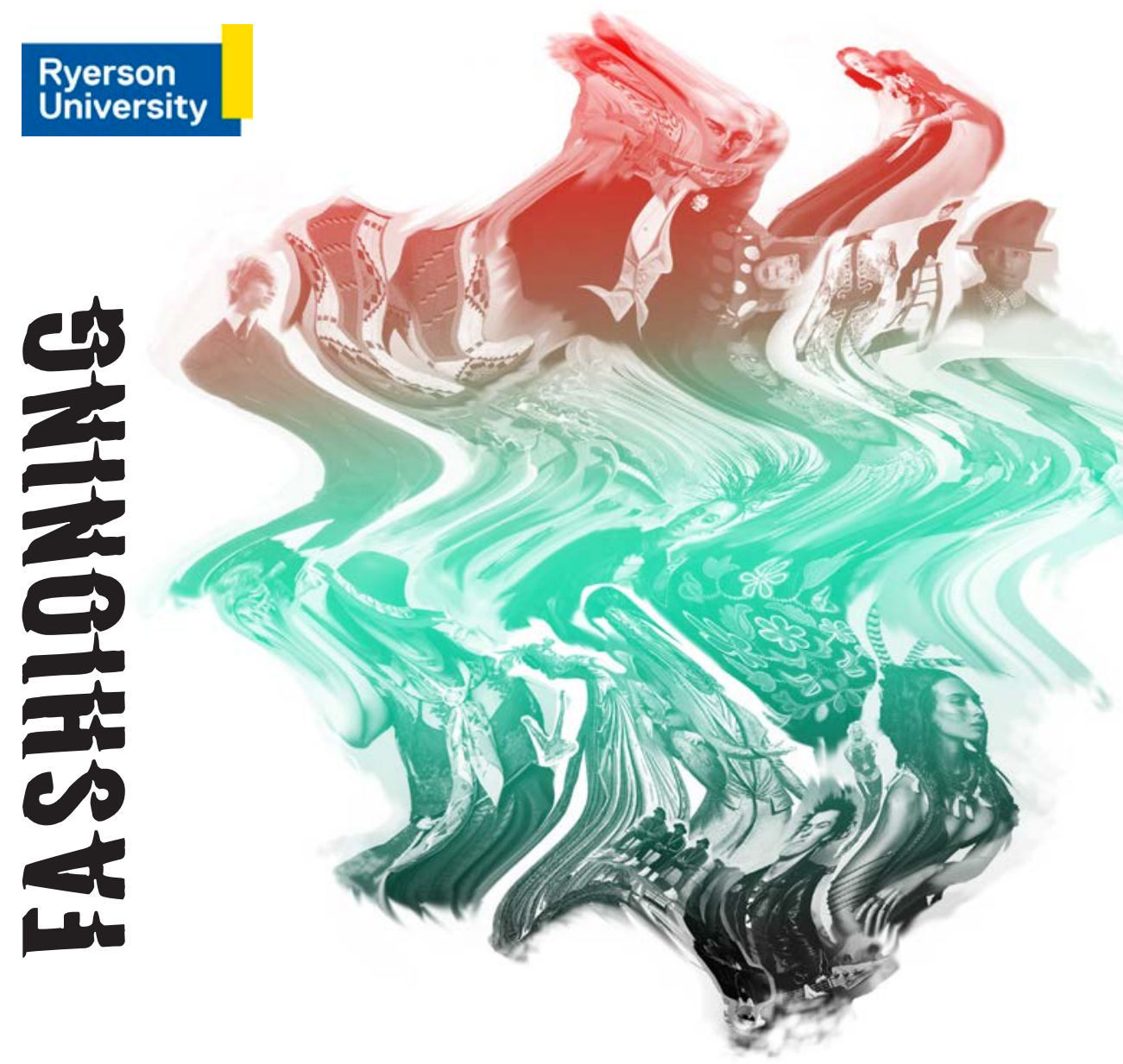

CALL FOR PARTICIPANTS

DECOLDNIZATION - What does it actually mean to you? Can fashion be an act of decolonization?

\section{DO YOU -}

\author{
$\square$ IDENTIFY AS CANADIAN FIRST \\ NATIONS, INUIT OR MÉTIS? \\ $\square$ HAVE AN INTEREST IN MAKING \\ ART AND/OR FASHION?
$\square$ WANT A BETTER UNDERSTANDING OF DECOLONIZATION? \\ $\square$ OVER 18 YEARS OLD
}

\section{FEBRUARY 16, 2019 IPM TO 4PM}

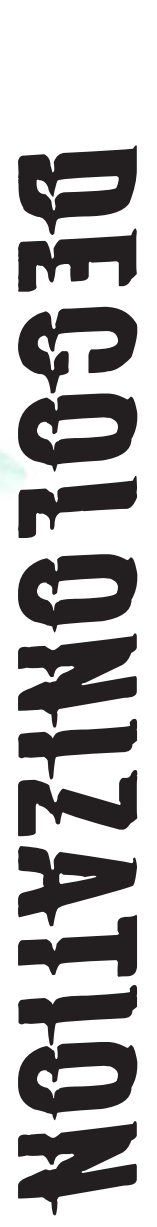

We would like you to take part in a EASHION HAGKIIG WORKSHOP, where we ask you to visually express decolonization. Bring your own garment to alter or deconstruct to the workshop. If you choose your garment will be presented in a group exhibition to share your story and interpretation.

The research is being conducted by Presley Mills, supervised by Dr. Ben Barry, for the partial completion for her Master's degree in Fashion. Participation is voluntary. Reviewed by the RU REB (2018-407) 


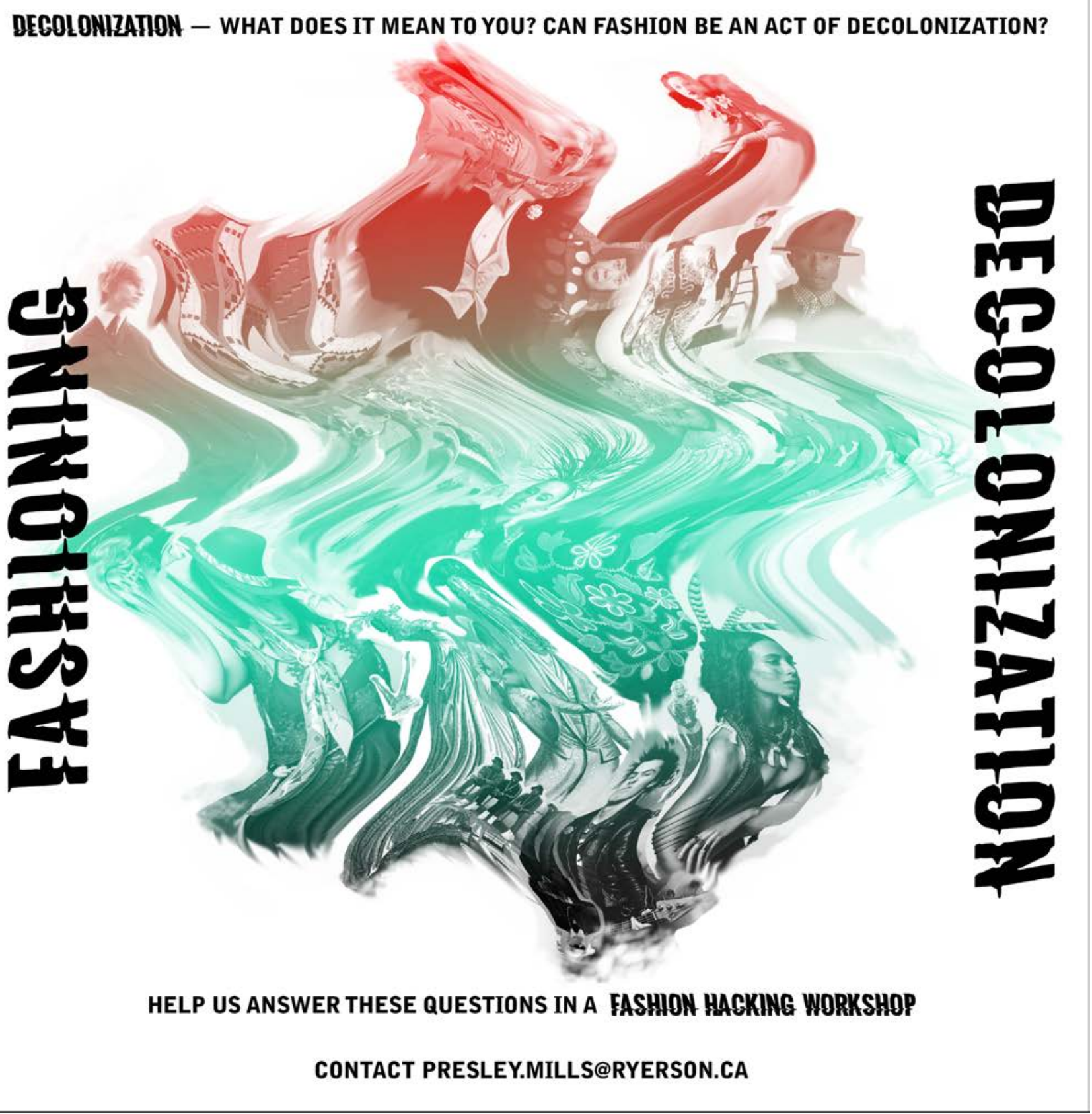

Social Media Caption (facebook \& instagram) :

Decolonization - What does it mean to you? Can fashion be an act of decolonization? Help us answer this by hacking up some clothing. We would like you to take part in a Fashion Hacking Workshop, where we ask you to visually express decolonization. Bring your own garment to alter or deconstruct to the workshop. If you choose your garment will be presented in a group exhibition to share your story and interpretation. Participants are eligible if they identify as First Nations, Inuit or Métis and are over the age of 18. The research is being conducted by Presley Mills, supervised by Dr. Ben Barry, for the partial completion for her Master's degree in Fashion. Participation is voluntary. To participate email presley. mills@ryerson.ca Please respond via email only. Reviewed by the RU REB (2018-407) 
Appendix 2: Workshop Inspiration Cards
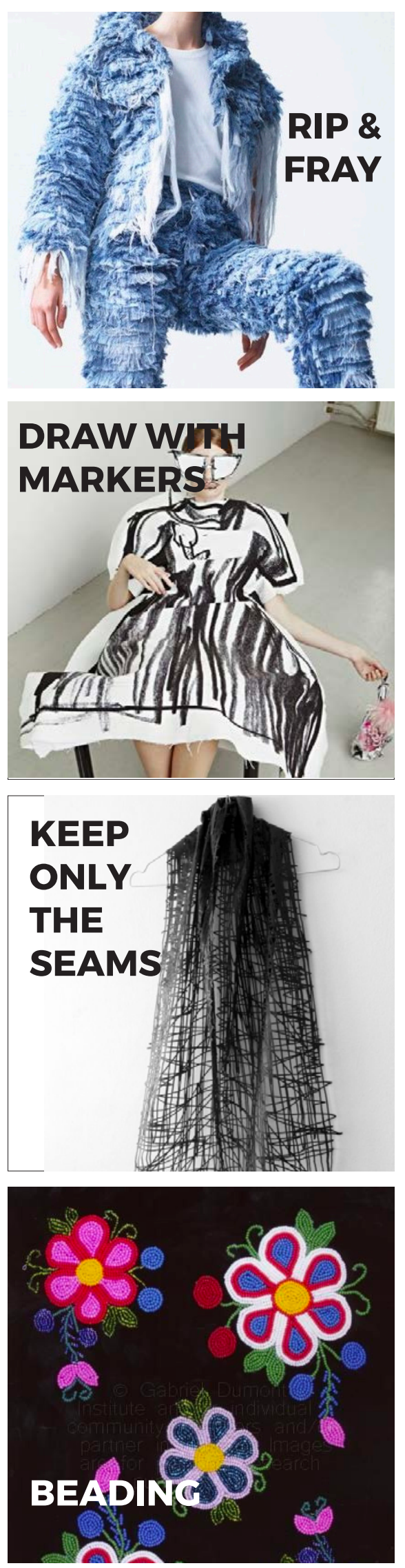
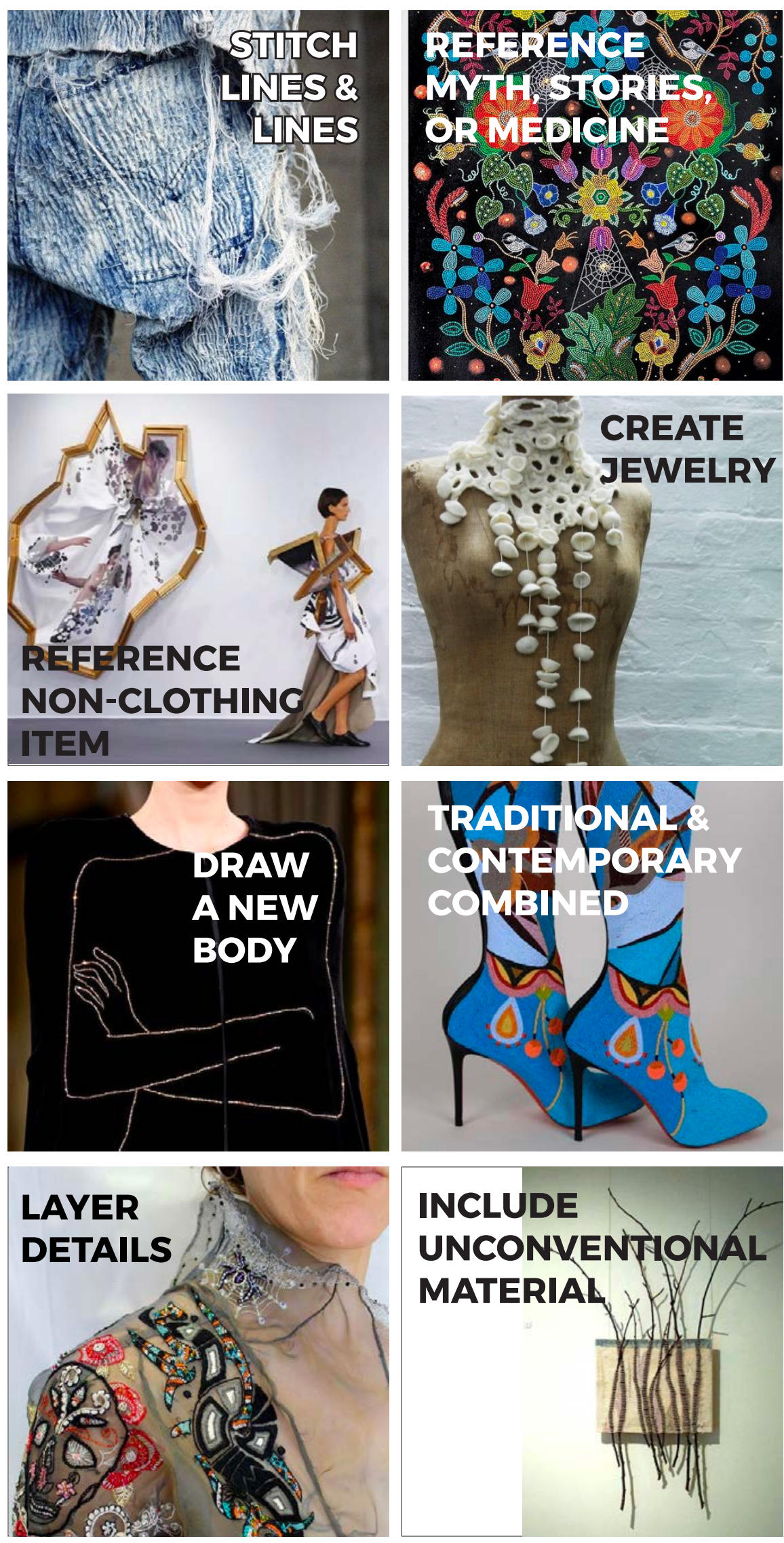
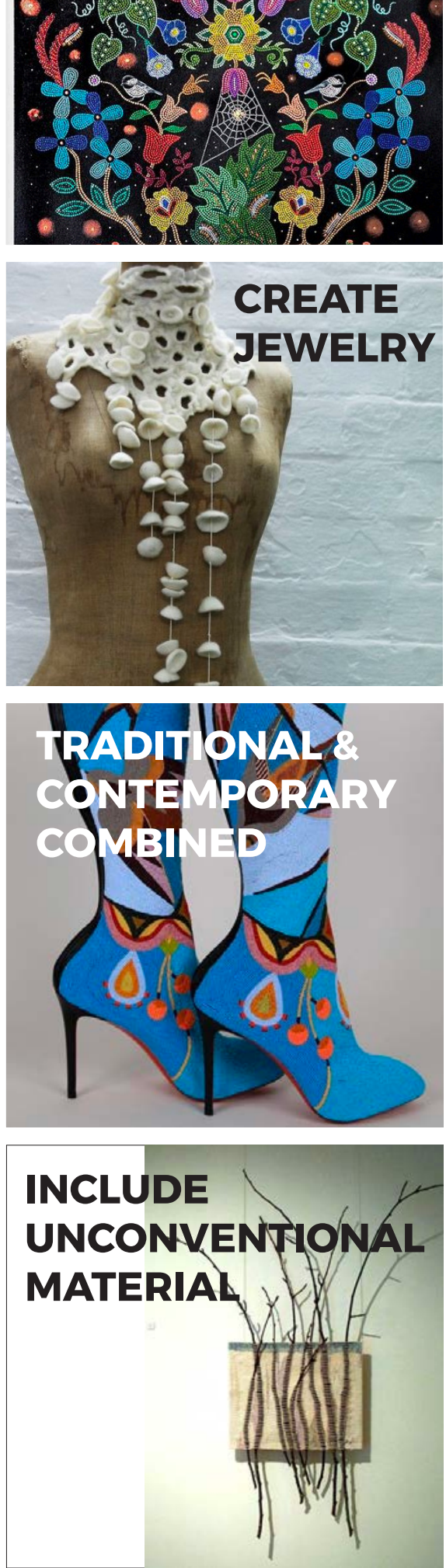

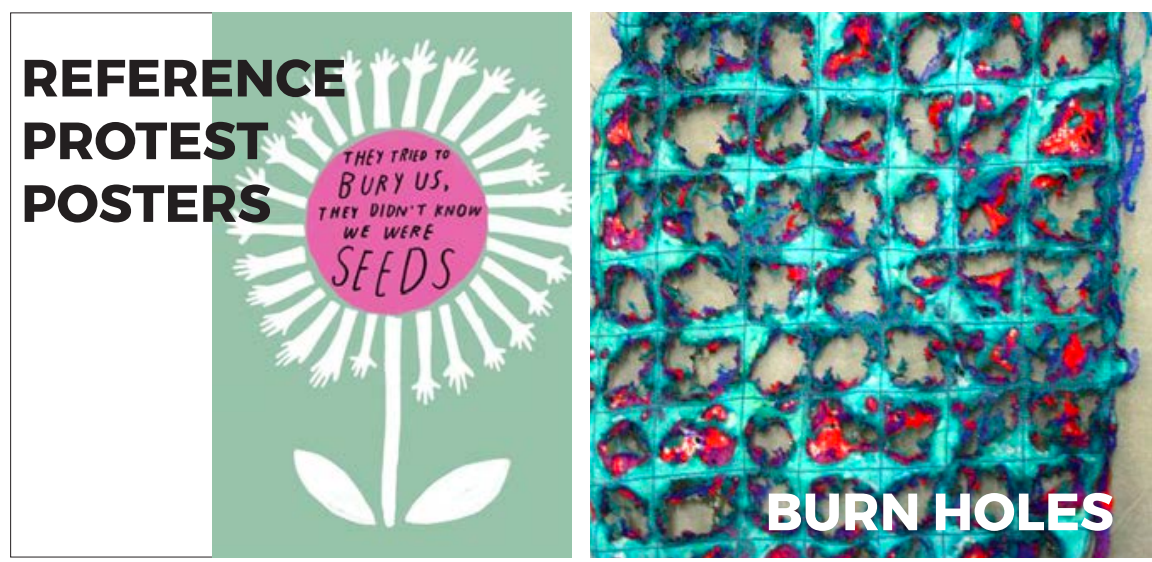

\section{CREATE LAYERS}
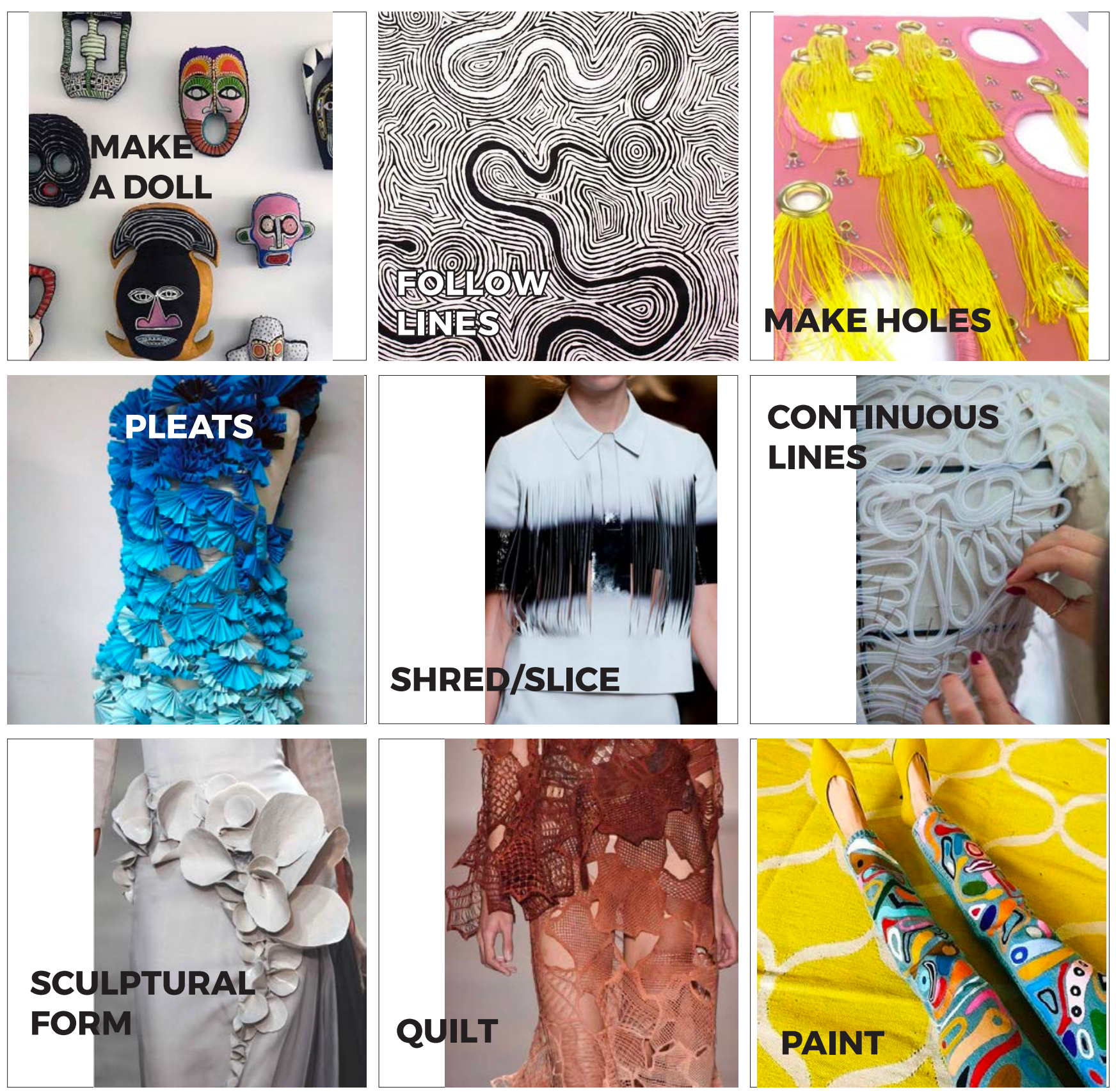

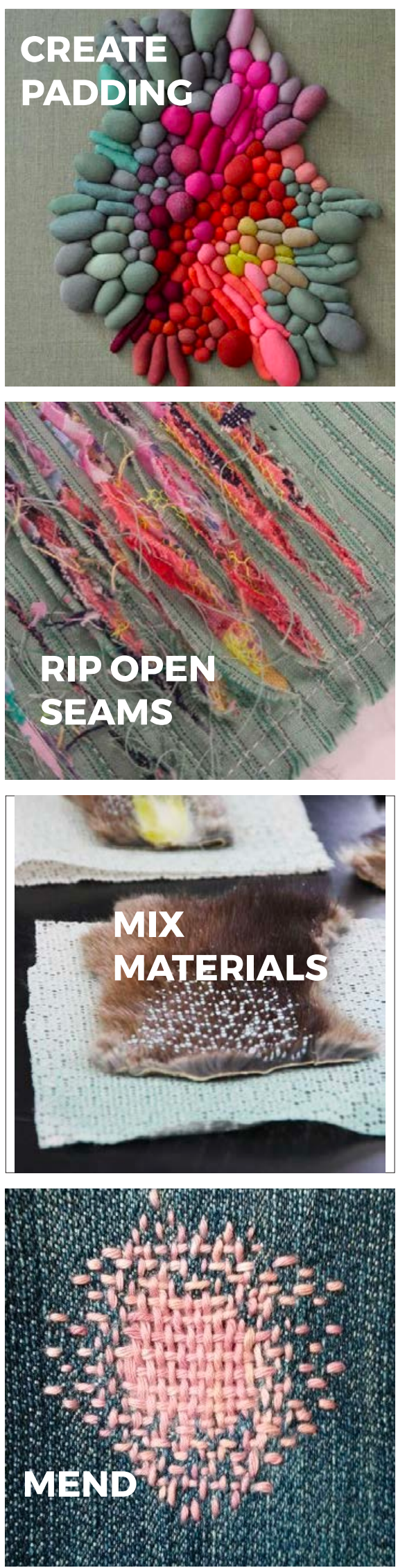
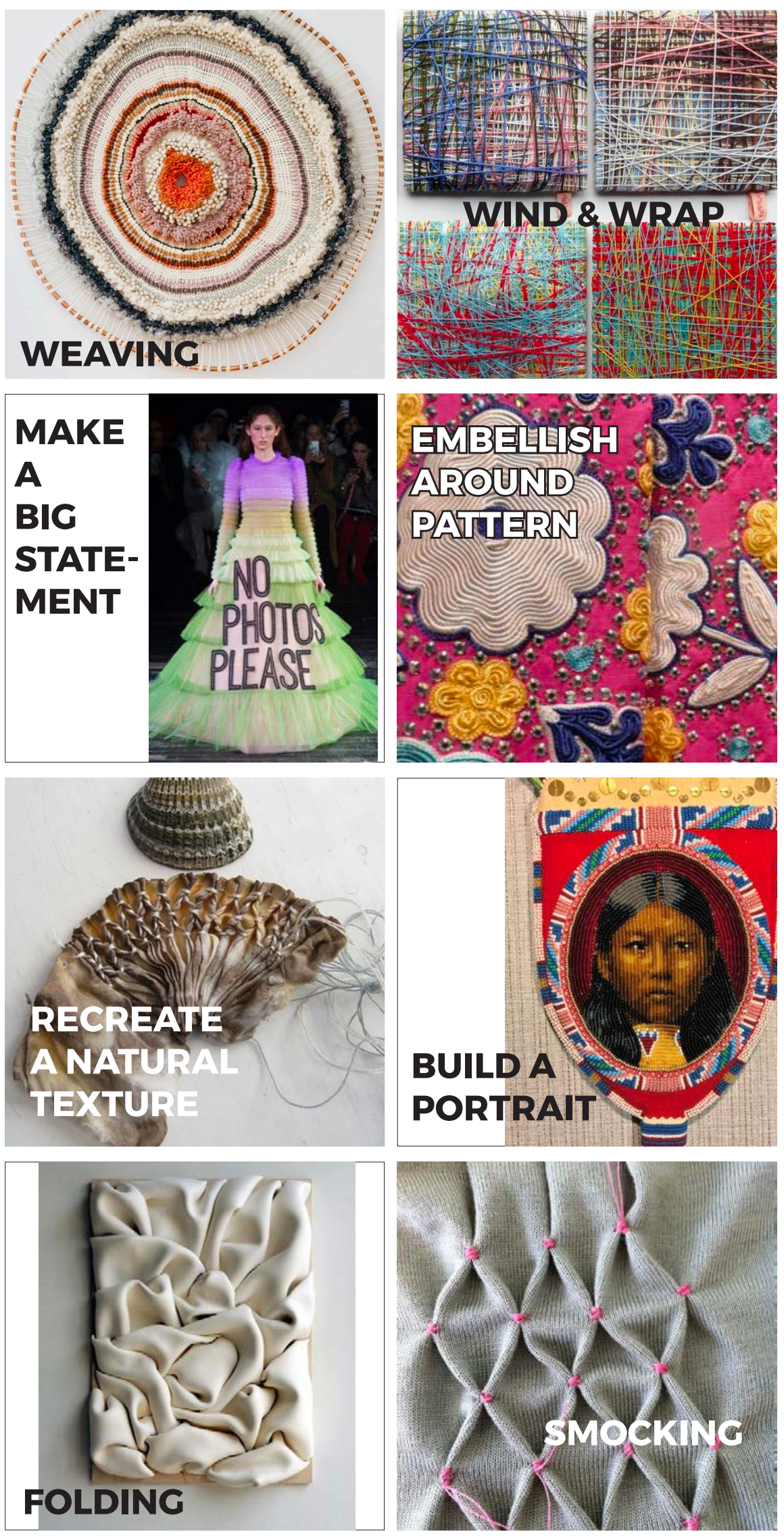


\section{Ryerson}

University

\section{Ryerson University \\ Consent Agreement to Participate in an Individual Interview}

You are being invited to participate in a fashion hacking workshop. Please read this consent form so that you understand what your participation will involve. Before you consent to participate, please ask any questions to be sure you understand what your participation will involve.

TITLE OF STUDY: Fashioning Decolonization

\section{INVESTIGATORS:}

This research study is being conducted by Presley Mills under the supervision of Dr. Ben Barry from the School of Fashion at Ryerson University for as part of her thesis project. The project is academic and findings will be shared through academic media, including journals, exhibitions, and conferences. The final project may also be included in the art portfolio of the Presley Mills. You are under no obligation to participate. Should you agree you participate, you are free to withdraw at any time without prejudice to pre-existing commitments. If you have any questions or concerns about the research, please feel free to contact me at presley.mills@ryerson.ca or 403-966-4272, or Dr. Ben Barry at bbarry@ryerson.ca or 416-979-5000, ext. 7318.

PURPOSE OF THE STUDY: This research is being conducted in partial fulfilment of a graduate degree, and the results you provide will contribute to Presley Mills' masters-level thesis which examines: How fashion can help individuals tackle larger social concepts and can be used to connect with their identity and imagine decolonized futures.

The workshops are being conducted to enrich the data gathered for the thesis' literature review and for the interpretation of the work created during the activity. They will allow you to voice any concerns or information you want to be included in the research in confidence.

\section{WHAT YOUR PARTICIPATION MEANS:}

If you agree, you will be asked to participate in a fashion hacking workshop and group interview lasting 3 hours. The date and location of the workshop are to be confirmed, but your preferences will be accommodated as much as possible. You will be expected to bring a garment (any type of clothing or accessory) to the activity. You will be provided with tools to help you remake, deconstruct, or alter the garment to reflect your interpretation of the work decolonization.

In addition to the activity, you can consent to be photographed during your participation in the fashion hacking workshop. You will be given the opportunity to exhibit your creation in the final display of the project (in the form of a fashion exhibition and photographs). You will be given the opportunity to review the media captured of you and can withdraw consent at any time.

The group interview will take place after the making period of the workshop. Following the interview, you will have access to the research findings, and you will be able to review images 
taken during the workshop. You may withdraw consent at any time, and you may also request the withdrawal of data you have provided.

\section{ACTIVITY OUTLINE:}

You will be in a group with 4-5 other participants. Prior to the activity please request any skills, tools or materials you hope to have access to and we will do our best to accommodate those requests. On the day of the fashion hacking workshop, please bring a garment you wish to reconstruct. Please bring a garment you would like to use for the activity. "Fashion Hacking" means we are disassembling and reconstructing a garment to change its function or meaning. When selecting a garment to bring, make sure it is something you are ready to potentially cut, deconstruct, decorate, etc. It will be a different garment when you complete the workshop! You will be provided with a selection of tools and notions to alter your garment. There will be 20 minutes dedicated to introductions, 2 hours and 10 minutes dedicated to making your garment, and 30 minutes discussion with the group about what you made. Your creation will be kept at the end of the workshop and returned to you after the exhibition (if you are choosing to participate). The exhibition will take place at Ryerson's Catalyst exhibition space during the month of April (exact dates TBA) and your garment will be returned after the exhibition is complete.

\section{WHAT ARE THE POTENTIAL RISKS TO YOU:}

There are potential risks involved should you agree to participate. While there are minimal physical risks, there are potential low psychological and social risks associated with this study: As a participant you might feel surprised, self-conscious, or uncomfortable sharing your work within the group or you might also feel obligated to participate; you may feel anxious answering questions about your personal experiences, or opinions about culture, and social organizations. To manage any social risk, such as being exposed or embarrassed, potential loss of privacy, you can choose to withdraw from the activity at any time or have your name remain confidential in the final exhibition of the work. The minimal physical risks are involved when using making tools, such as scissors or sewing needles. To minimize the risk, the researcher will explain the safety hazards and instruction prior to the activity. As the workshop takes place in a group setting, there is a risk to your confidentiality, as you will interact with other participants and they may discuss their experience outside of the workshop. Your participation is completely voluntary, and there will be no negative repercussions should you choose to not participate, from Ryerson University. You may partially or completely withdraw at any point during the research. You may skip questions or choose not to answer anything. You may ask to view the data review the findings before the thesis is submitted for defence. Should you prefer, interviews can take place in a secure location, I will do my best to accommodate. If you experience as emotional distress as a result of discussing personal topics, please withdraw from participation at any time. You can contact http://www.distresscentre.com/ or https://www.mymentalhealth.ca/ get-help/help-right-now/ for additional support.

POTENTIAL BENEFITS: The aim of the project is to give voice to untold experiences and specifically explore unexamined narratives of contemporary Indigenous experiences. This research could benefit society in general through the advancement of knowledge, otherwise, I cannot guarantee that you will receive any benefits from participating in this study. Your participation may contribute your self-awareness, healing or empowerment. 


\section{CONFIDENTIALITY:}

Please note that participation in this workshop will not be anonymous: the primary researcher and your fellow participants will be able to identify you. The activity will take place in a group setting, which limits the confidentiality as participants may discuss their experience outside of the activity. However, for the exhibition confidentiality can be maintained to the best of my ability by protecting your information from unauthorized use, disclosure, modification, loss or theft. You may select whether a pseudonym is assigned to you personally or if you would like your real name used.

\section{DATA STORAGE}

The physical data collected will include your demographic form, the physical copy of the consent form, and the garment produced during the workshop. The digital data collected will include the audio recording of the workshop and the photographs. The digital data will have technical safeguards, such as password protected computers/encrypted files for digital data. Only the primary researcher will have access to the raw data collected: photographs, and audio recordings.

\section{HOW YOUR INFORMATION WILL BE PROTECTED AND STORED:}

To protect your information, original notes from the interview will be destroyed and the transcribed data and photographs will be stored by the researcher in a password protected digital file. Should you wish to be assigned a pseudonym, your name and information will not appear in the data, final thesis, or any publications that might come from the research. Data collected will be accessible only by the investigator. Following the study the physical copies of the research data will be destroyed; the encrypted file containing the digitized research data will be kept on the primary investigator's computer for a minimum of 2 years: The data you provide may be used in future scholarly publications or my $\mathrm{PhD}$ dissertation.

DATA DISSEMINATION: The object created during the activity may be presented publicly in an exhibition of all the products of the fashion hacking workshop. This may take the form of a fashion show, exhibition, social media feed, or magazine. The information collected during the activity and interview will be used in the creation of my thesis. The contents of which will be used in academic outlets, such as academic publications, reports, or conferences. The participants will be informed of any pending publication and/or acceptance in a scholarly journal. before the thesis is submitted for review, a proof version will be made available to research participants by email. Ample time will be given for final review/input from participants.

COSTS TO PARTICIPATION: Participants are expected to bring a personal garment to the activity. That cost my varied based on the individual but there will be no compensation for this cost.

COMPENSATION FOR INJURY: By agreeing to participate in this research, you are not giving up or waiving any legal right in the event that you are harmed during the research.

VOLUNTARY PARTICIPATION AND WITHDRAWAL: Participation in this study is completely voluntary. You can choose whether to be in this study or not. If any question makes you uncomfortable, you can skip that question. You may stop participating at any time. If you choose to stop participating, you may also choose to not have your data included in the study. Your choice of whether or not to participate will not influence your future relations with Ryerson University, or the investigators Presley Mills or Dr. Ben Barry. 
QUESTIONS ABOUT THE STUDY: If you have any questions about this research, please feel free to contact the researcher, Presley Mills, or her supervisor, Dr. Ben Barry (see below for contact information).

Presley Mills

MA Candidate, Ryerson University presley.mills@ryerson.ca

403-966-4272

Dr. Ben Barry

Associate Professor of Equity, Diversity \& Inclusion, Ryerson University School of Fashion

416-979-5000, ext. 7318

bbarry@ryerson.ca

This study has been reviewed by the Ryerson University Research Ethics Board. If you have questions regarding your rights as a participant in this study please contact:

Research Ethics Board

c/o Office of the Vice President, Research and Innovation

Ryerson University

350 Victoria Street

Toronto, ON M5B 2K3

416-979-5042

rebchair@ryerson.ca

\section{CONFIRMATION OF AGREEMENT}

Your signature below indicates that you have gone over the information in this agreement and have had a chance to ask any questions you have about the study. Your signature also indicates that you agree to participate in the study and have been told that you can change your mind and withdraw your consent to participate at any time. You have been given a copy of this agreement. You have been told that by signing this consent agreement you are not giving up any of your legal rights.

Name of Participant (please print)

Assign a pseudonym? YES NO

Participants' signature:

Date:

1. I also agree to be audio recorded for the purposes of this study. I understand how these recordings will be stored and transcribed. (Leave blank if you do not agree). 
Signature of Participant

Date:

2. I also agree to be photographed during the activity for the purposes of this study. I understand how these photos will be stored (Leave blank if you do not agree).

\section{Signature of Participant}

Date:

3. I also agree to be allow the work I create during the activity to be exhibited purposes of this study. (Leave blank if you do not agree).

Signature of Participant

Date:

3a. If I choose not to exhibit by creation, I consent to the having it documented via photograph.

Signature of Participant

Date:

4. I consent to having images of my worked shared on the following platforms:

[ ] The gallery exhibition

[ ] RUAL Digital Depository (Ryerson University)

[ ] Exhibition pamphlets/book

[ ] Instagram (Researcher's or Ryerson's)

You will be able to review any data collected from your interview before it is included in any public scholarly works: such as the thesis presentation or scholarly journals. You will be emailed a draft of the research for review. Would like to be notified by email to review the data collected?

\section{YES NO}

If you have any questions about your rights or treatment as a research participant in this study, please contact the Ryerson University Research Ethics Board at rebchair@ryerson.ca or (416) 979-5042.

Please keep a copy of this page for your future reference. This study has been approved by the Research Ethics Board at Ryerson University 


\section{Appendix 4: Workshop Plan and Materials}

\section{Work period:}

$2+$ hours

Room set up: One large round table set up. Encourage discussion and collaboration.

Facilitator/researcher will float around and ask people how things are going and if they need help.

Introduction questions:

How you idenitify?

What did you bring to the workshop?

\section{Share / Discussion of Results}

20 minutes

Spend a few minutes discussing the changed garment as a group and the makers can talk about their intention/goal.

Questions for maker:

How would you describe your project?

Did the process contribute to your personal understanding of decolonization?

\section{Materials:}

Acrylic Paint Set (24 colours), paint brushes, beads, scissors, sewing needles, thread, embroidery thread, yarn, scrap material, hot glue gun \& glue sticks, sharpies, note paper \& pencils, branches, dowels, seam rippers, duct tape, \& scrap fabric. 


\section{Appendix 5: Post Workshop}

\section{Fashioning Decolonization \\ Definitions \& Resource Link}

Decolonization: Decolonization once viewed as the formal process of handing over the instruments of government, is now recognized as a long-term process involving the bureaucratic, cultural, linguistic and psychological divesting of colonial power.

- Decolonization is about shifting the way Indigenous Peoples view themselves and the way nonIndigenous people view Indigenous Peoples.

- Decolonization restores Indigenous world views, culture and traditional ways, and replaces Western interpretations of history with Indigenous perspectives of history.

- Decolonization challenges policies designed for assimilation.

- Decolonization encourages reclaiming family, community, culture, language, history, traditions, and control via self-governance, treaties or negotiations.

Indigenization: Make indigenous; subject to native influence.

- Indigenization incorporates Indigenous ways of knowing and doing.

- Indigenization requires non-Indigenous people to be aware of Indigenous worldviews and to respect that those worldviews are equal to other views.

- Indigenization recognizes validity of unique and diverse Indigenous worldviews, knowledge and perspectives.

Both decolonization and indigenization require the cooperation of Indigenous and non-Indigenous people, governments, organizations and institutions.

Colonialism: the policy or practice of acquiring full or partial political control over another country, occupying it with settlers, and exploiting it economically.

Settler Colonialism: Settler colonialism is a type of colonialism that functions through the replacement of indigenous populations with an invasive settler society that, over time, develops a distinctive identity and sovereignty. Canada is a settler colonial state.

The TRC definition of reconciliation:

"... Reconciliation is about establishing and maintaining a mutually respectful relationship between Aboriginal and non-Aboriginal peoples in this country. In order for that to happen, there has to be awareness of the past, an acknowledgement of the harm that has been inflicted, atonement for the causes, and action to change behaviour."

You can access the TRC reports here: http://nctr.ca/reports.php 
List of links and pdfs provided to participants via shared google drive folder post-workshop. Examples include readings and examples of artists, designers and musicians demonstrating decolonization in their work.

- Curtis Oland. Learn more at: https://www.vogue.com/vogueworld/article/curtis-oland-londonfashion-week-exhibit-somerset-house?fbclid=IwAR1F7-_sgCAR9Ktb_0IC0JHhqV-9WyWzbyoy7V QZk1rfMtvCz4Lxep9ML1g

- A recognition of being: reconstructing native womanhood, By Kim Anderson

- From Appropriation to Subversion: Aboriginal Cultural Production in the Age of Postmodernism, By Peter Kulchyski

- Evan Ducharme. Learn more at: https://www.evanducharme.com/

- Bethany Yellowtail. Learn more at: https://byellowtail.com/pages/about-us

- Decolonization is Not a Metaphor, by Eve Tuck and K. Wayne Yang

- Kehine Wiley (Artist African Americans/ Decolonization). Learn more at: http://kehindewiley.com/

- Kent Monkman. Learn more at: http://www.kentmonkman.com/

- Decolonizing Feminism: Challenging Connections between Settler Colonialism and Heteropatriarchy. By Maile Arvin, Eve Tuck, and Angie Morrill

- Research as Resistance: Critical, Indigenous, \& anti-oppressive approaches. By Leslie Brown \& Susan Strega

- Ryan Presley (Australian Indigenous/decolonization) Learn more at: http://ryanpresley.com.au/

- Settler Colonialism and Cultural Studies: Ongoing Settlement, Cultural Production, and Resistance. By Aimee Carrillo Rowe and Eve Tuck

- Sonny Assu. Learn more at: https://www.sonnyassu.com/

- Xiuhtezcatl Martinez. Learn more at: https://i-d.vice.com/en_us/article/9k7gbv/xiuhtezcatl-breakfree-album-indigenous-peoples-day 


\section{Works Cited}

Aboriginal peoples in Canada: Survey Results from the 2016 Census. (2017). Statistics Canada. Retrieved from http://www.statcan.gc.ca/daily-quotidien/171025/dq171025a-eng.htm

Anderson, K. (2000). A recognition of being: reconstructing native womanhood. Toronto: Sumach Press.

Andrews, J. (2002). “Irony, Métis Style: Reading the Poetry of Marilyn Dumont and Gregory Scofield." Canadian Poetry, 50 (spring/summer). Retrieved from https://www.brickbooks.ca/reviews/irony-metis-style-reading-the-poetry-of-marilyn-dumont-and-gregory-scofield-reviewed-by-jennifer-andrews/

Andersen, C. (2014). "Colonial Genocide in Indigenous North America." Western Historical Quarterly, Autumn, pp. 366-367.

Andersen, C., (2014). "Métis": Race, Recognition, and the Struggle for Indigenous Peoplehood. Vancouver: UBC Press.

Angelique, H. \& Mulvey, A. (2012). "Feminist Community Psychology: The Dynamic Co-Creation of Identities in Multilayered Contexts." Journal of Community Psychology, 40 (1), pp. 1-10.

Arvin, M. Tuck, E. Morrill, A. (2018). “ Decolonizing Feminism : Challenging Connections between Settler Colonialism and Heteropatriarchy." Feminist Formations, 25(1), pp. 8-34.

Aziz, T. (2009). "Shifting the frame: from critical reflective arts practice to practice-based research." Journal of Media Practice, 10(1), pp. 69-80.

Barman, J. \& Evans, M. (2009). "Reflections on Being, and Becoming, Metis in British Columbia." BC Studies, 161(Spring), pp. 59-91.

Barnard, M. (1996). Fashion as Communication. London: Routledge.

Battiste, M. (2000). Reclaiming Indigenous Voice and Vision. Vancouver: UBC Press.

Baudrillard, Jean. (1993). Symbolic Exchange and Death. New York, NY: Sage. (pp. 87-99).

Birkbeck, J. (2014). "Fashioning authentic selves: Second-hand clothing and the materialization of enduring values." Critical Studies in Fashion \& Beauty, 5(1), pp. 111-124. 
Calvo, M. \& De Rosa, A. (2017) "Design for social sustainability. A reflection on the role of the physical realm in facilitating community co-design.” The Design Journal, 20(1), pp. 1705-1724.

Castellano, M., \& Archibald, L. and DeGagné, M. (2019). From truth to reconciliation: Transforming the Legacy of Residential Schools. Ottawa: Aboriginal Healing Foundation.

Dorion, L. (1997). Emerging Voices of Métis Women. Gabriel Dumont Institute.

Stolen Lives: The Indigenous Peoples of Canada and the Indian Residential Schools. Facing History \& Oursleves, (2019). Retrieved from https://www.facinghistory.org/stolen-lives-indigenous-peoples-canada-and-indian-residential-schools

Ferguson, T. (2008). “The Lizottes of Fort Vermilion and the pre-1900 Evolution of a Métis Community.” Alberta History, Autumn.

Flisfeder, M. (2010). "A Bridge to Reconciliation: A Critique of the Indian Residential School Truth Commission." The International Indigenous Policy Journal, 1(1).

Fontaine, L. (2017). "Redress for linguicide: Residential schools and assimilation in Canada." British Journal of Canadian Studies, 30 (2), pp. 183-204.

Métis Rights. Government of Canada, (2018). Retreived from https://www.aadnc-aandc.gc.ca/ eng/1100100014413/1100100014414

A Brief Definition of Decolonization and Indigenization. Indigenous Corporate Training Inc. (2019). Retrieved from https://www.ictinc.ca/blog/a-brief-definition-of-decolonization-and-indigenization

Hunsinger, J. \& Schrock, A. (2016). “The Democratiziation of Hacking and Making.” Sage Journals: New Media \& Society, 18 (4), pp. 535-538.

Keulemans, G. (2016). “The Geo-cultural Conditions of Kintsugi." The Journal of Modern Craft, 9(1), pp. $15-34$.

King, T. (2012). The Inconvenient Indian: A Curious Account of Native People in North America. Canada: Penguin Random House.

Laenui, P. (2007). Federalism and the Rights of Indigenous Peoples: A Hawaiian Perspective. Ottawa: Aboriginal Healing Foundation. 
Leclair, C. (2002). “'Memory alive': race , religion , and Metis identities. Essays on Canadian Writing.” Essays on Canadian Writing, 75, pp. 159-176.

Logan, T. (2019). "A Métis Perspective on Truth and Reconciliation." From Truth to Reconciliation: Transforming the Legacy of Residential Schools. pp. 69-89.

Magnet, V. (2012). "Can Research Become Ceremony? Performance Ethnography and Indigenous Epistemologies." Canadian Theatre Review, 151 (Summer), pp. 30-36.

McNeill, L. (2008). "Fashion and woman's self-concept: a typology of self-fashioning using clothing." Journal of Fashion Marketing and Management: An International Journal, 22(1), pp. 82-102.

Merkle, D. \& Mallet, M. (2018). "Lost and Found in (Self-)Translation: From Colonial to Post-colonial Contexts." TranscUlturAl, 10 (1), pp. 1-8.

Mithlo, N. (2011). "Blood Memory and the Arts: Indigenous Genealogies and Imagined Truths." American Indian Culture and Research Journal, 35 (4), pp. 103-118.

Niezen, Ronald. (2017). Truth and Indignation: Canada's Truth and Reconciliation Commission on Indian Residential Schools, Second Edition, University of Toronto Press. Retrieved from: https://ebookcentral-proquest-com.ezproxy.lib.ryerson.ca/lib/ryerson/detail.action?docID=5181477.

Otto von Busch. (2009). "Engaged Design and the Practice of Fashion Hacking: The Examples of Giana Gonzalez and Dale Sko." Fashion Practice, 1(2), pp. 163-185.

Riello, G. (2012). “The object of fashion: Methodological approaches to the history of fashion.” Journal of Aesthetics and Culture, 3, pp. 1-9.

Rivera-Santana, C. (2018). "Monstrous Anthropology: The Appearance of Colonisation.” Third Text, 31(4), pp. 567-580.

Sawchuk, J. (2001). "Negotiating and Identity: Metis Political Organizations, the Canadian Government, and Competing Concepts of Aboriginality." American Indian 2uarterly, 25(1), pp. 73-92.

Smith, N. (2002). "Oral History and Grounded Theory Procedures as Research Methodology for studies in Race, Gender, and Class." Race, Gender \& Class, 9(3), pp. 121-138.

Steibhauer, P. (2002). “Situating Myself in Research." Canadian Journal of Native Education, 25(2), pp. 183187. 
Tuck, E. \& Yang, K. (2012). “Decolonization is not a Metaphor.” POC Online Classroom. Retrieved from http://www.poconlineclassroom.com/blog/2017/2/17/rad-reading-decolonization-is-not-a-metaphor

Wilson, S. (1998). Research is Ceremony: Indigenous Research Methods. Halifax: Fernwood Publishing. 